المهابير التّريوية والةتبـة لتصمبمر برامه وتطبرة

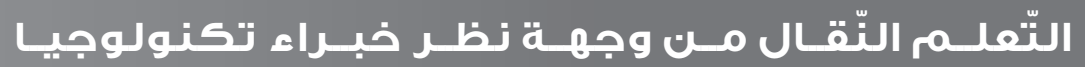

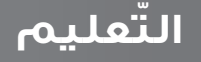

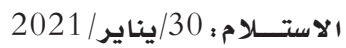

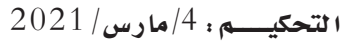

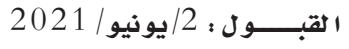

أحمد محمد المباريدي)(1*)

(c) 2021 University of Science and Technology, Yemen. This article can be distributed under the terms of the Creative Commons Attribution License, which permits unrestricted use, distribution, and reproduction in any medium, provided the original author and source are credited.

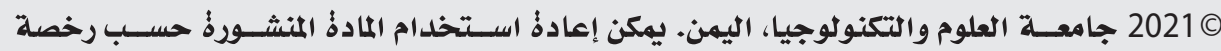
مؤسسة المشاع الإبداعي شريطة الاستشهاد بالمؤلف والمجلة. 


\section{المعايير التّربوية والفنية لتصميمج بـرامج وتطبيقات التّعلمم النّققال مـن

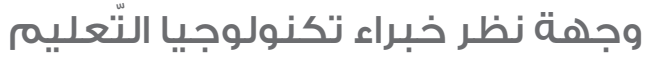

\section{الملخص:}

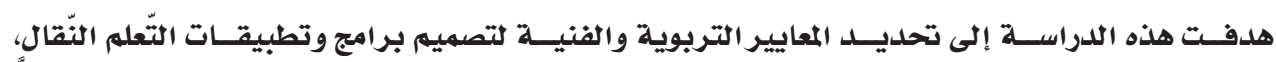

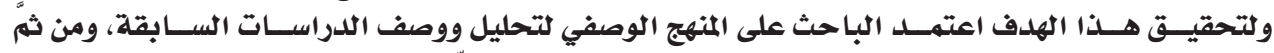

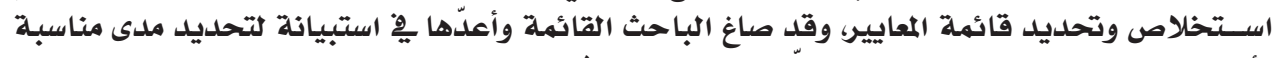

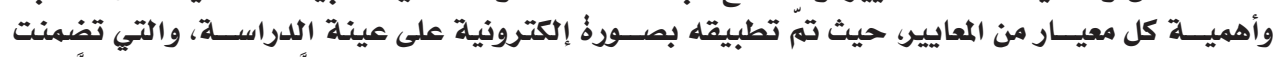

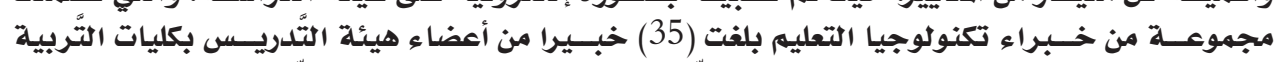

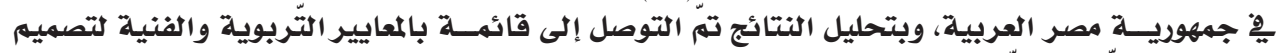

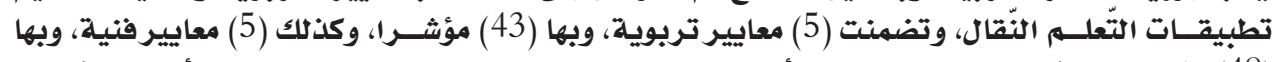

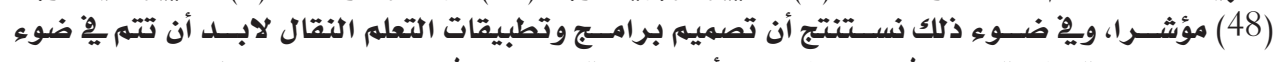

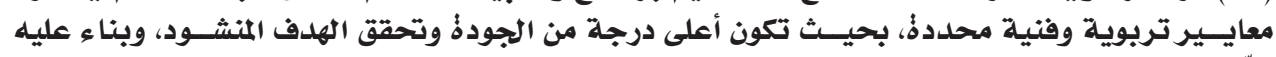

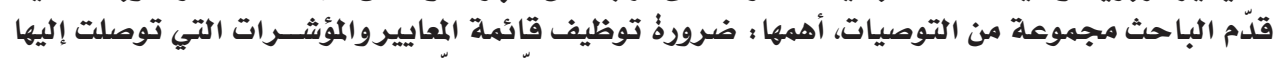

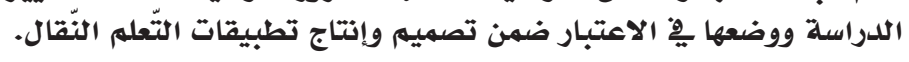
الكلمات المفتاحية : معايير التصميم التَّربوية، معايير التصميم الفنية، تطبيقات التّعلم النّقال. 
أحمد محمد المباريدي

المجلد الرابع عشر العدد (48) 2021م مدمد المياريلم

\title{
Educational and Technical Standards for Designing Mobile Learning Applications from the Perspective of Educational Technology Experts
}

\begin{abstract}
:
This study aimed to identify the educational and technical standards for designing mobile learning applications. To achieve the research objective, the descriptive method was adopted to analyze and describe the previous literature in order to deduce standards. A list of standards was developed in a form of questionnaire in order to identify significance and relevance of standards. The tool was applied in an electronic form to a sample of (35) educational technology experts from the teaching staff members in Faculties of Education in Egypt. After the analysis of the results, a list of educational and technical standards for designing mobile learning applications was identified. These included (5) educational standards with a total of (43) indicators, and (5) technical standards with a total of (48) indicators. In light of these results, a number of recommendations were proposed.
\end{abstract}

Keywords: educational standards, technical standards, mobile learning applications. 


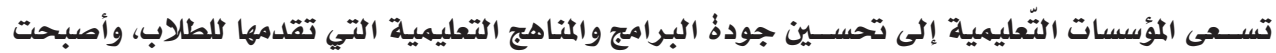

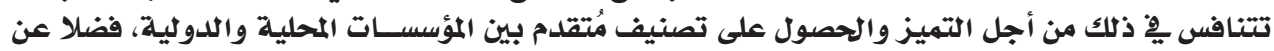

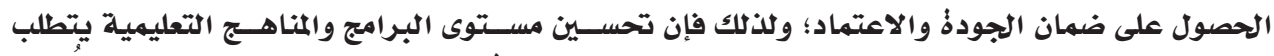

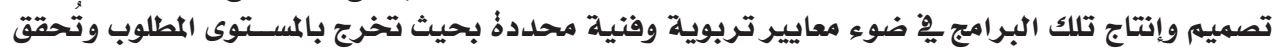
الهدف المرجوذٌ منها.

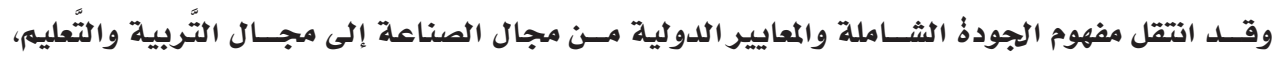

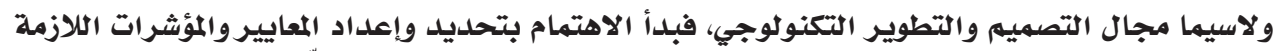

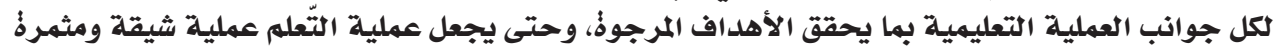

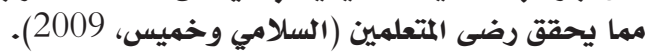

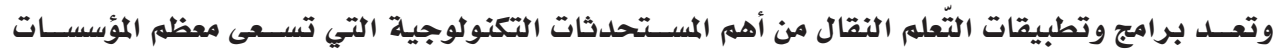

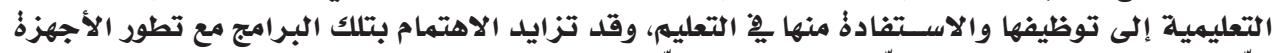

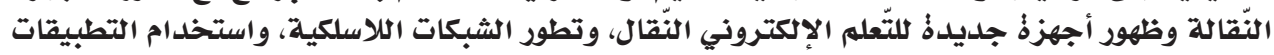

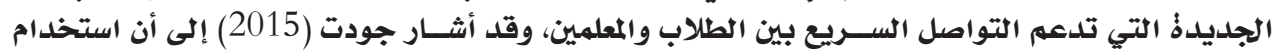

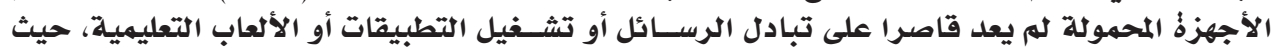

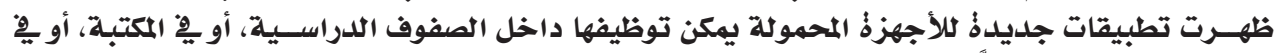

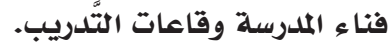

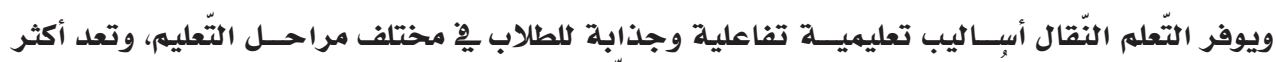

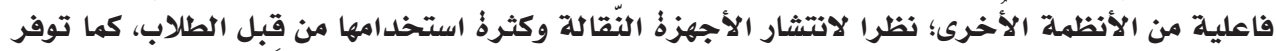

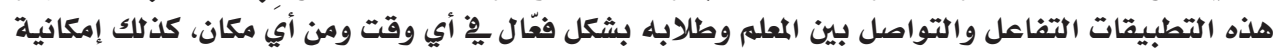

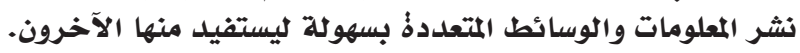

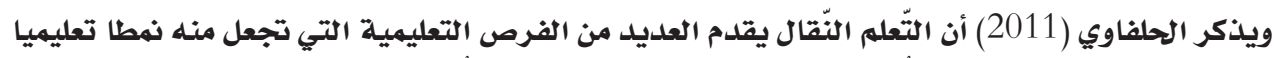

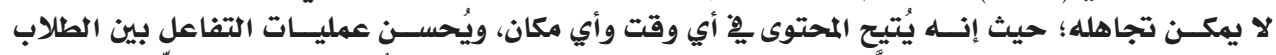

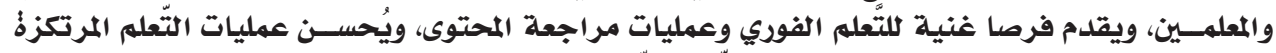

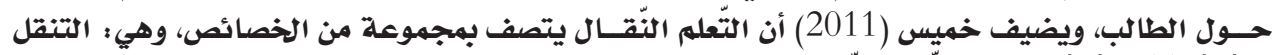

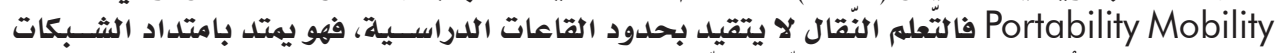

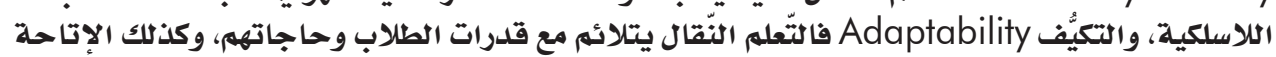
Availability

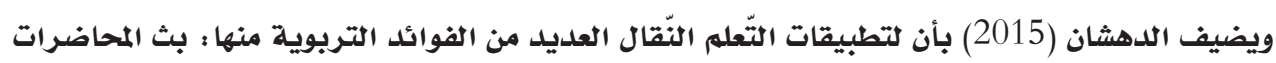

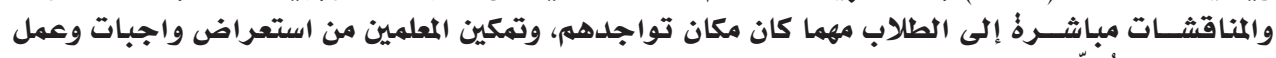

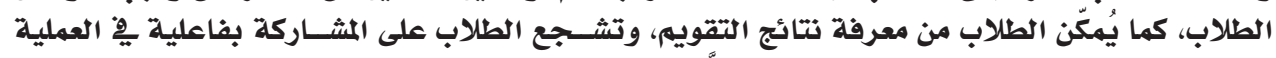

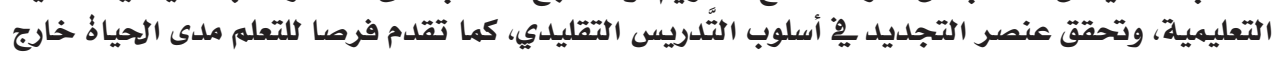

$$
\text { الفصول الدراسية. }
$$

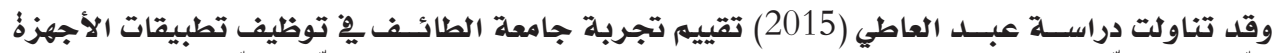

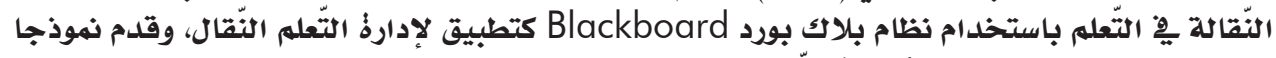

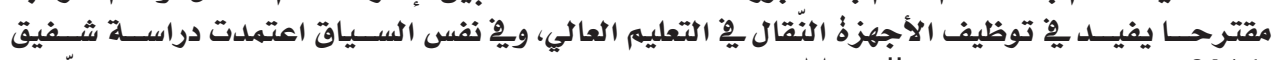

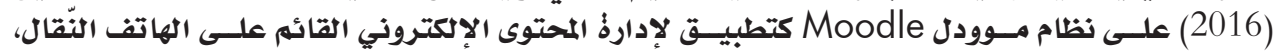

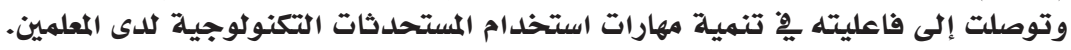




$$
\text { المجلد الرابع عشر العدد (48) 2021م المباريدي }
$$

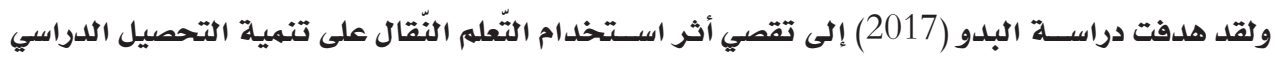

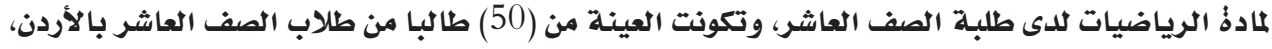

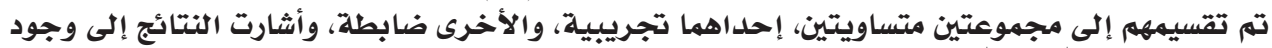

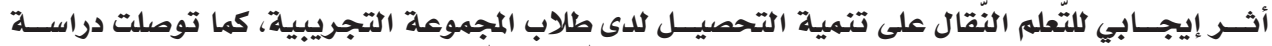

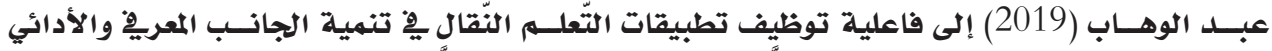

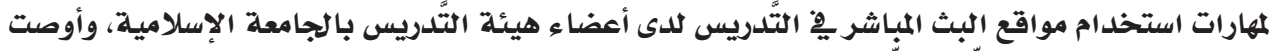

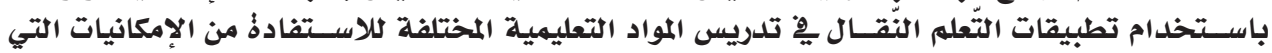

تقدمها.

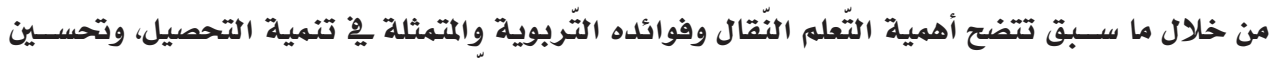

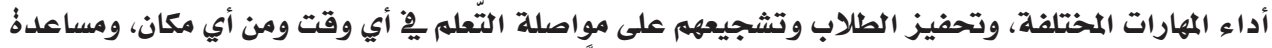

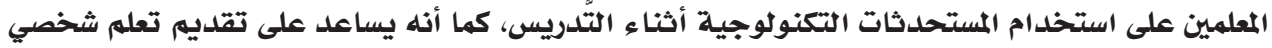

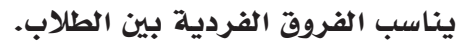

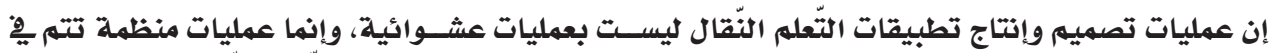

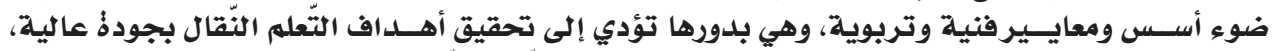

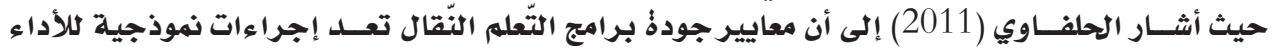

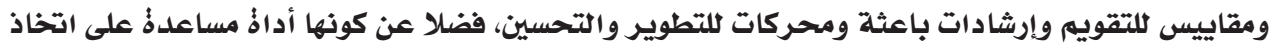

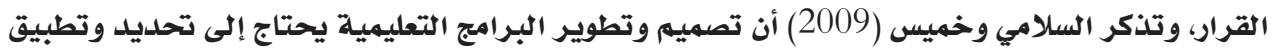

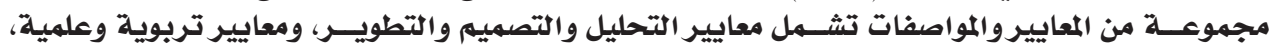

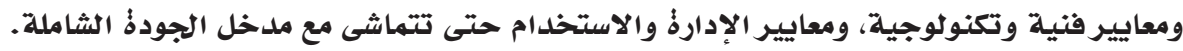

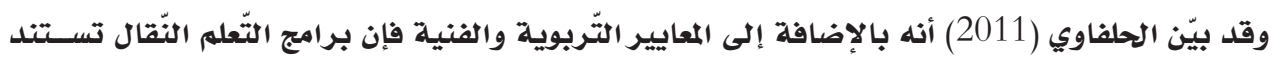

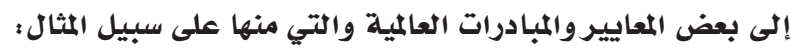

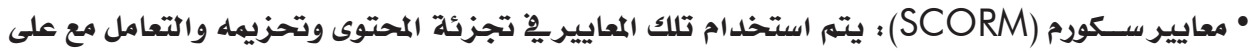

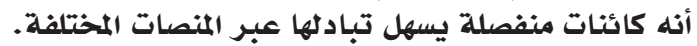

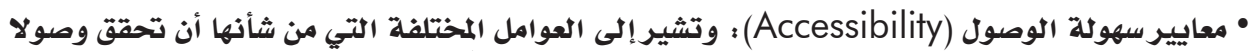

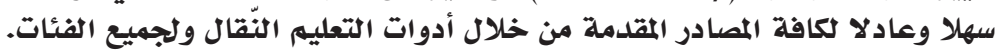

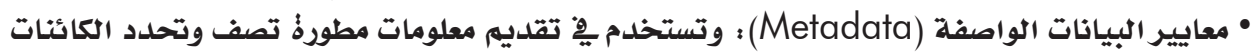

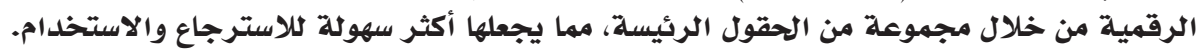

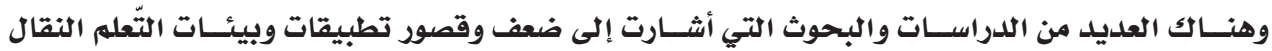

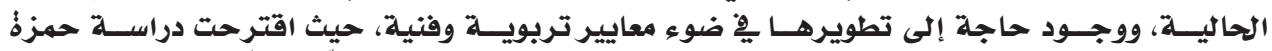

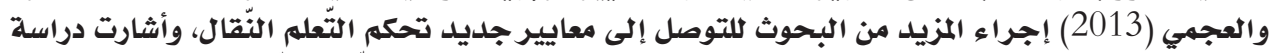

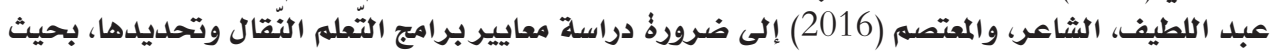

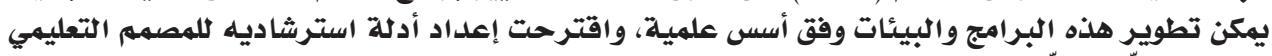

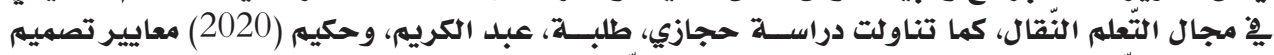

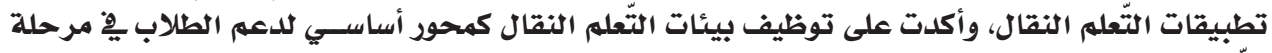

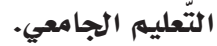

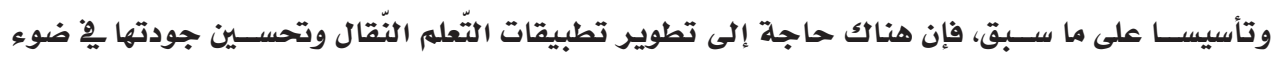

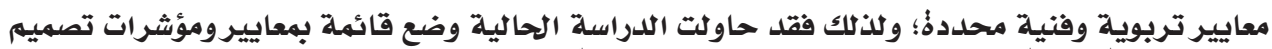

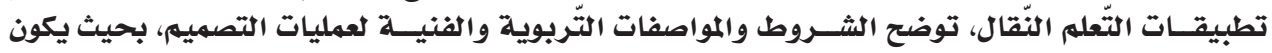

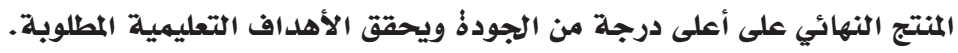




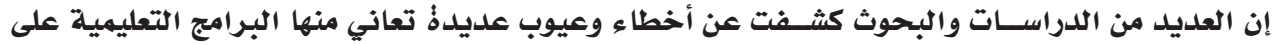

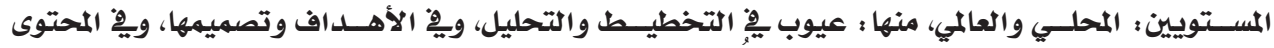

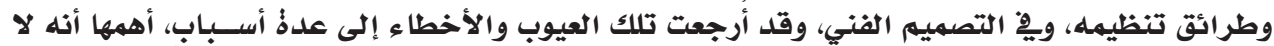

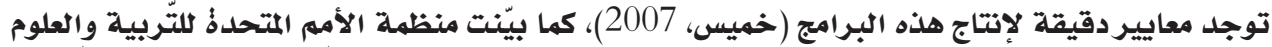

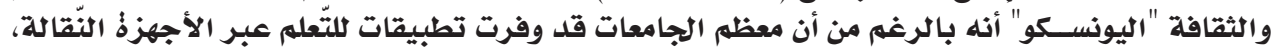

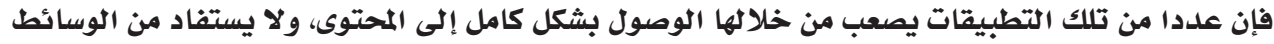

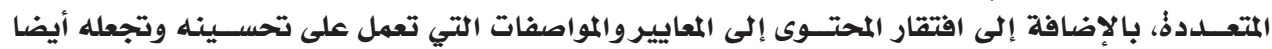

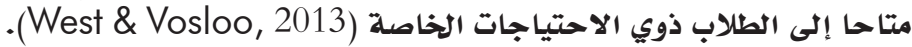

وخلال جائحة كورونا Covid-19 وما بعلدها، واتجاه معظم المؤسسات التعليمية إلى تطبيق نظام التّعلم

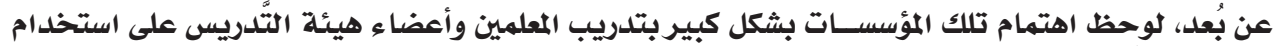

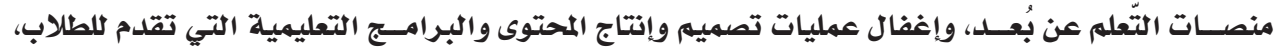

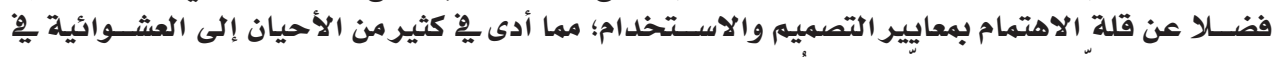

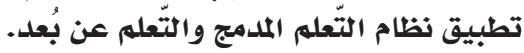

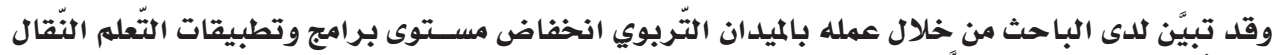

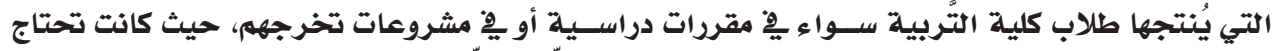

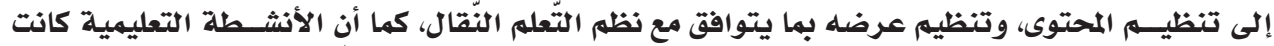

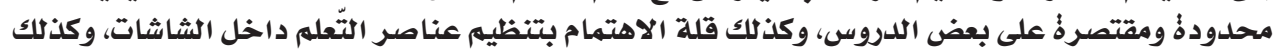

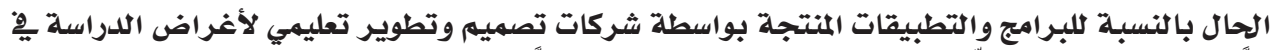

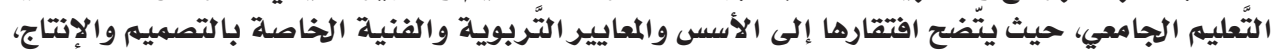

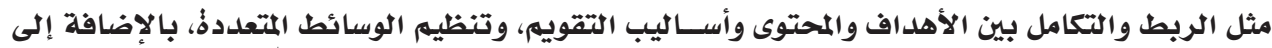

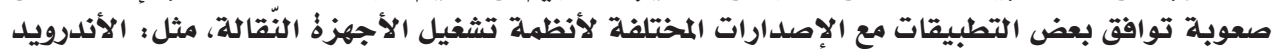
. IOS Android

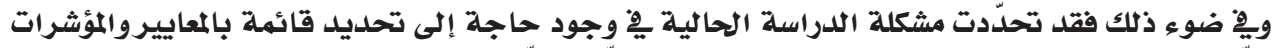

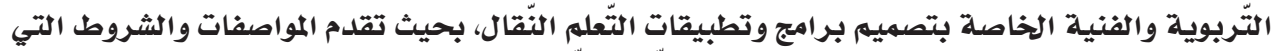

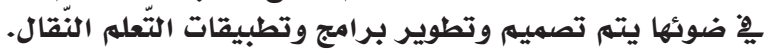

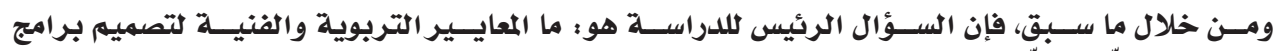

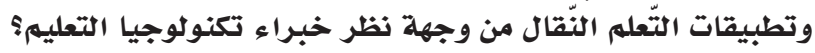
والذي سيتم الإجابة عليه من خلال السؤالين الفرعيين الآتيين :

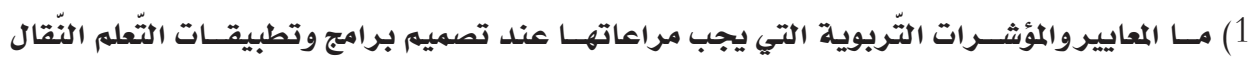
₹(M-Learning)

2) مــا المعاييروالمؤشـــرات الفنية التي يجــب مراعاتها عند تصميـهـم برامج وتطبيقــات التّعلم النّقال $\S(M$-Learning $)$ أهداف الدراسة:

سعت الدراسة الحالية إلى تحقيق الأهداف الآتية ؛

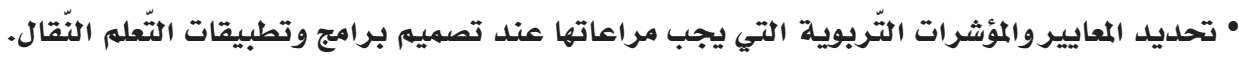

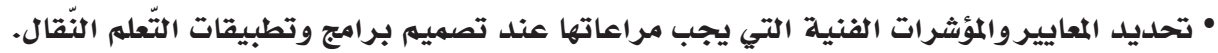




$$
\text { المجلد الرابع عشر العدد (48) 2021م المبدمي المحيدي }
$$

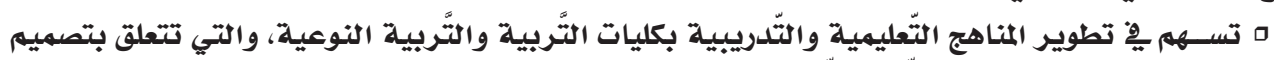

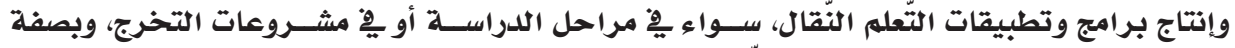

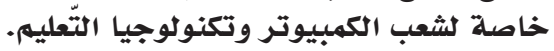

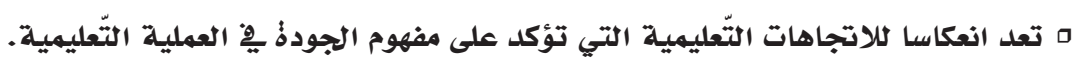

$$
\text { ثانيا : الأهمية العملية - التطبيقية : }
$$

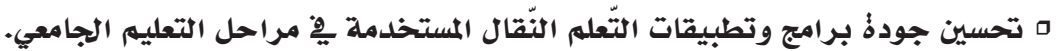

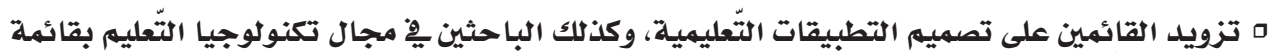

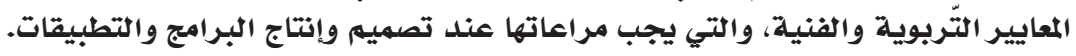

$$
\text { مصطلحات الدراسة : }
$$

ه المعايير:

يُعرّف خميس (2007، 101) المعيار Standard بأنه "عبارةٌ عامة واسعة تصف ما ينبغي أن يكون عليه

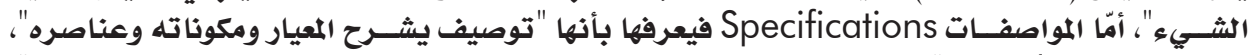

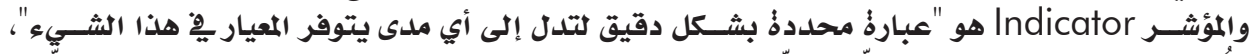

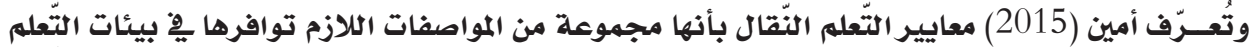

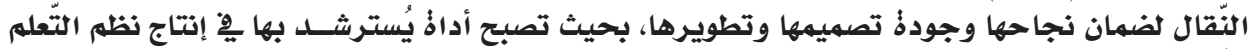

النّقال والمحافظة لضمان نجا حلى استمراريتها.

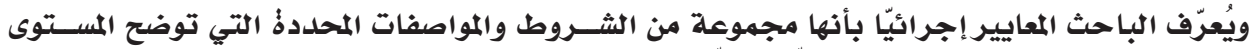

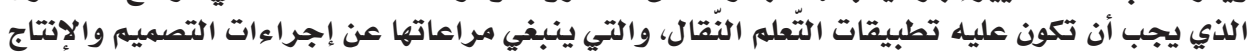

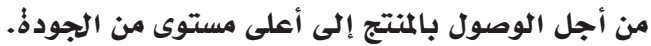
ه تطبيقات التّعلم النّقال :

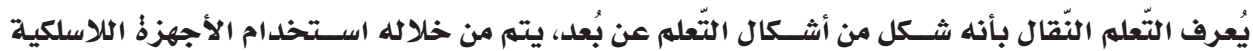

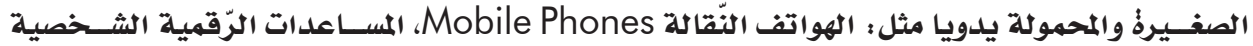

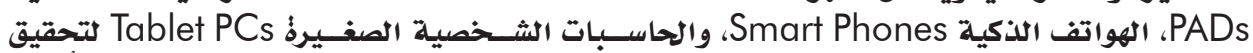

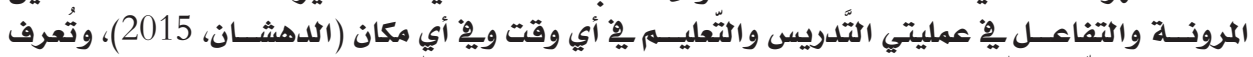

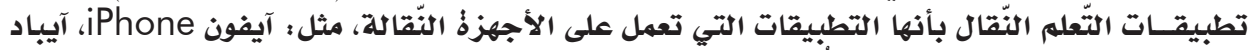

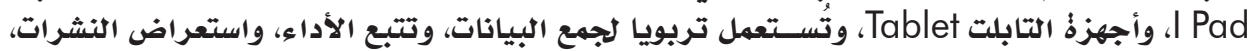

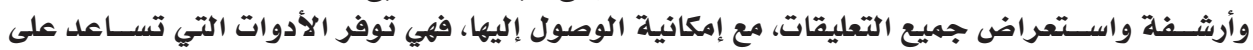
العمل بكفاءةٌ أكبر (Jarmuz-Smith, 2012).

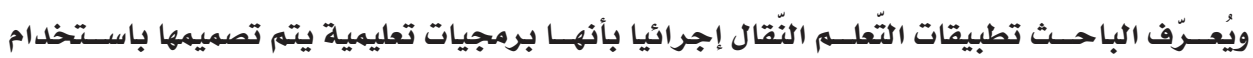

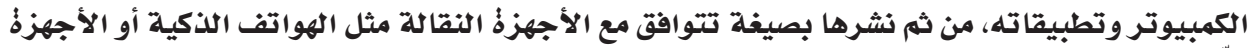

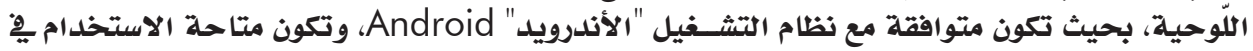
أي وقت ومن أي مكان. 


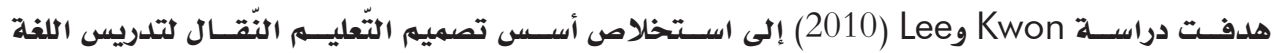

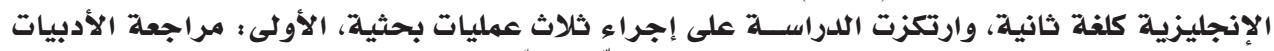

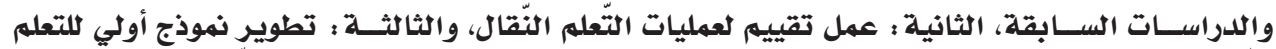

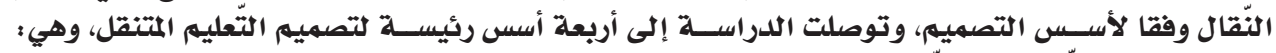

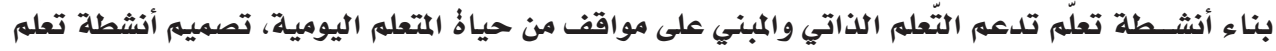

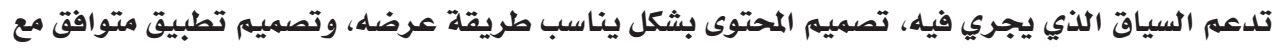

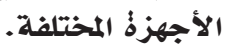

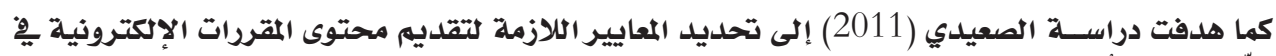

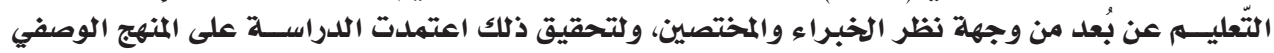

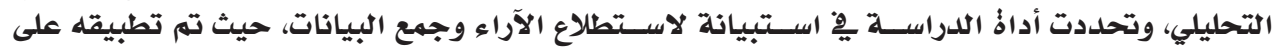

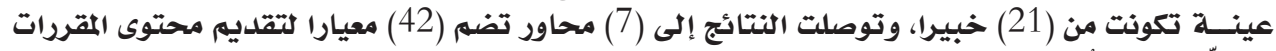

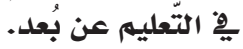

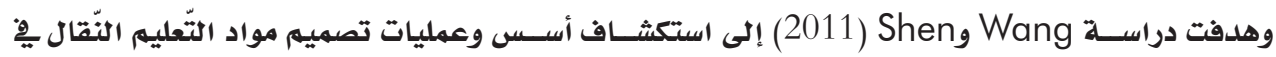

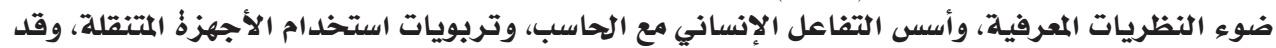

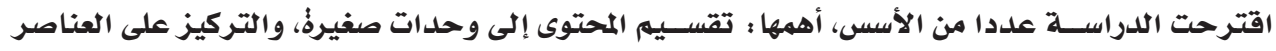

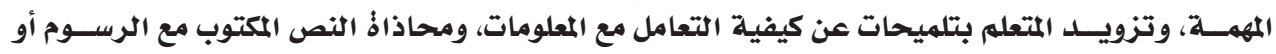

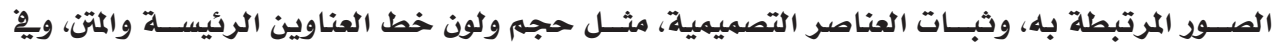

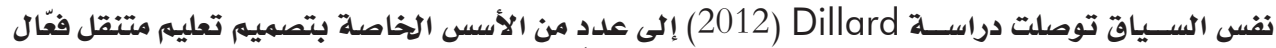

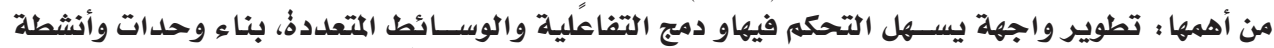

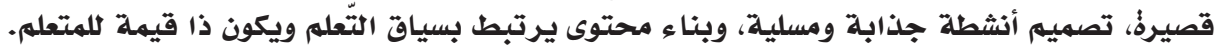

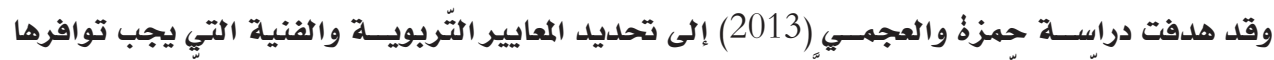

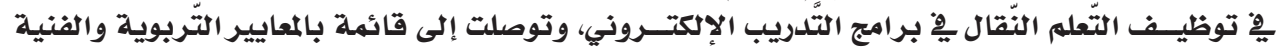

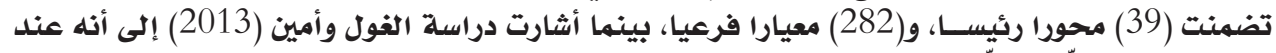

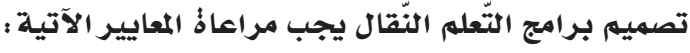

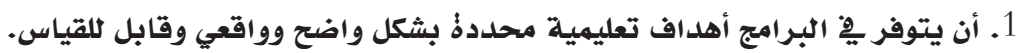

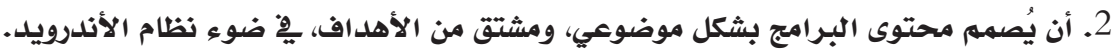

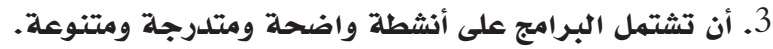

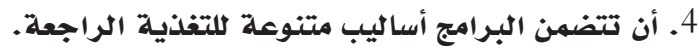

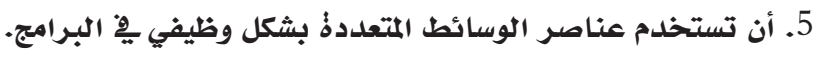
6. أن تكون الروابط وأساليب التصفح محلددةٌ وبسيطة.

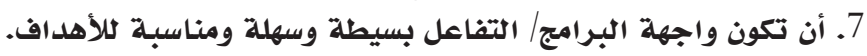
8. أن يتسم البرنامج بسهولة وقاجة البرامج اليفاعل الاستخدام.

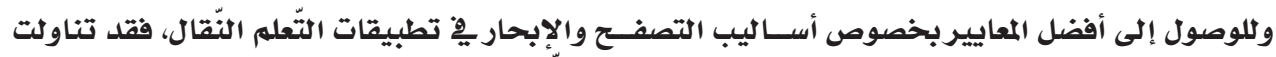

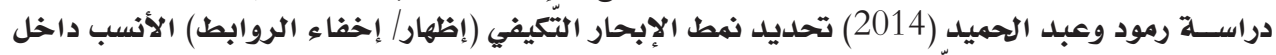

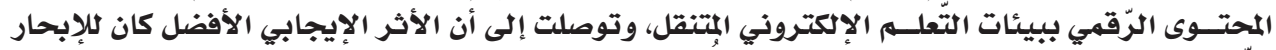

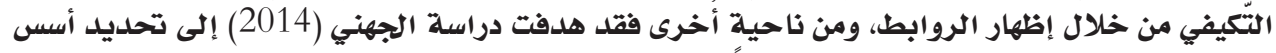

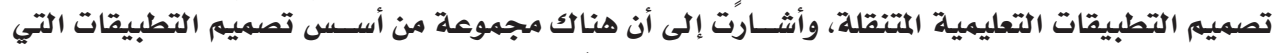

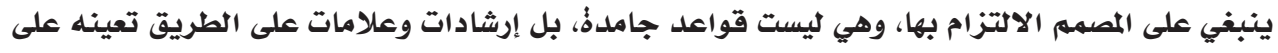




$$
\begin{aligned}
& \text { أحمد محمد المباريدي } \\
& \text { المجلد الرابع عشر العدد (48) 2021م آحمد مدياريد }
\end{aligned}
$$

التحكم يف الشكل النهائي للتطبيق؛ ليحقق وظيفته ضمن إطار تربوي وفني يجذب انتب انتباه المتعلم، وتوصلت

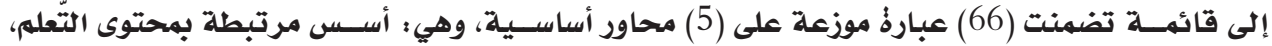

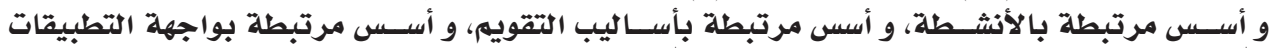
التّعليمية، وأسس مرتبطة بوسائط التطبيقات التّعليمية.

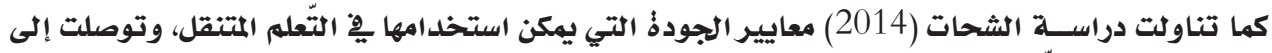

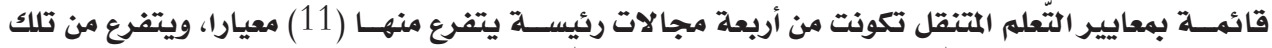

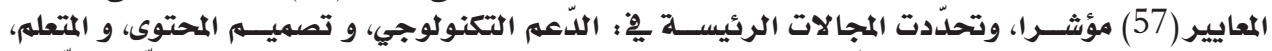

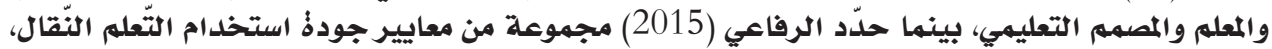

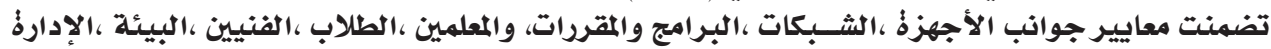

والاعتماد الأكاديمي.

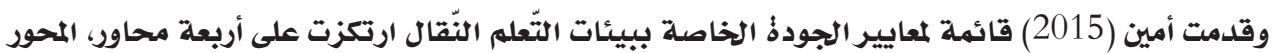

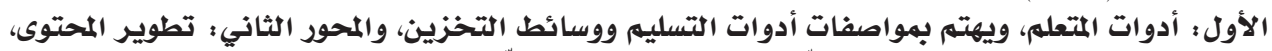

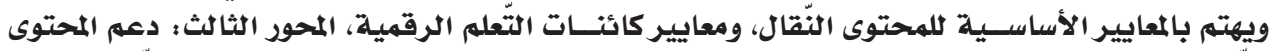

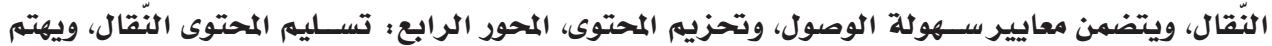

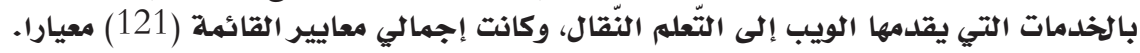
ولقد هلدفت دراســة العساف ودرادكة (2016) إلى بنـاء نموذج مقترح لبيئة تعلم إلكترونية للتّعلم النقال

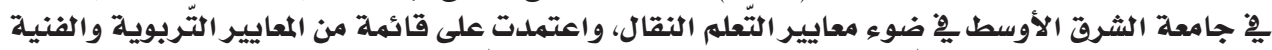

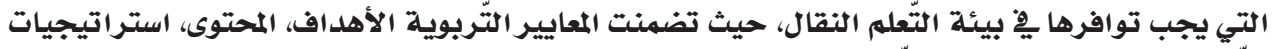

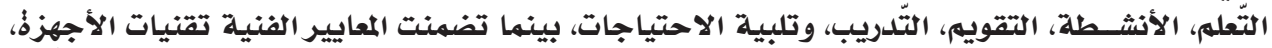

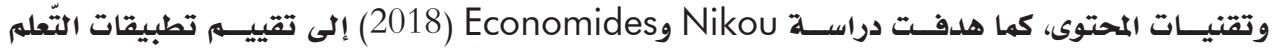

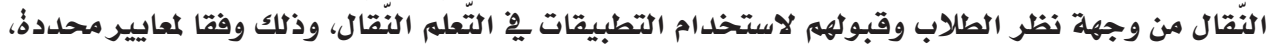

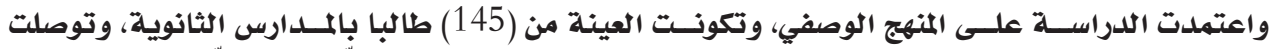

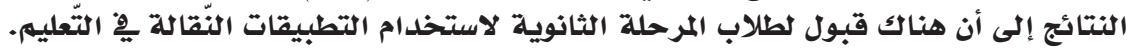

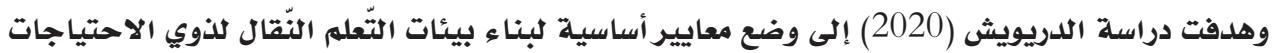

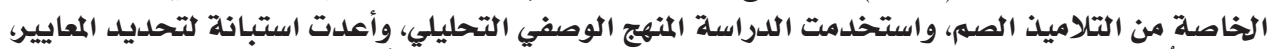

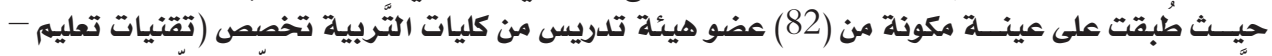

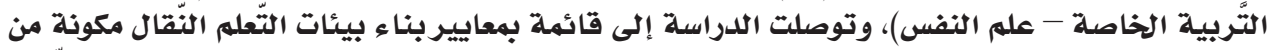

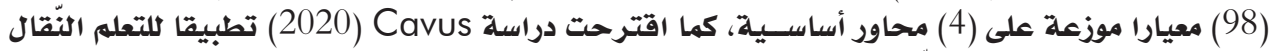

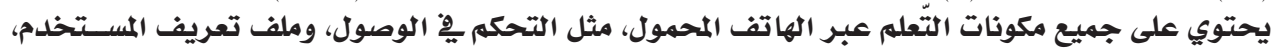

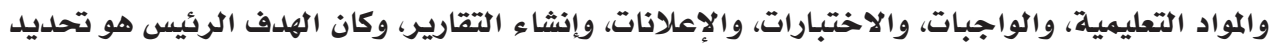

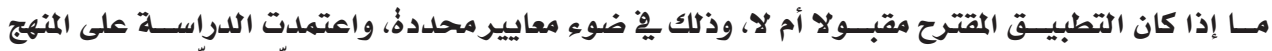

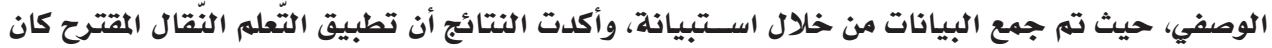

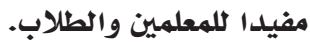

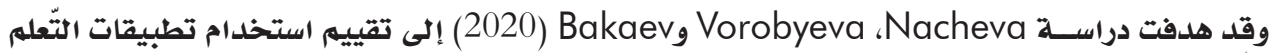

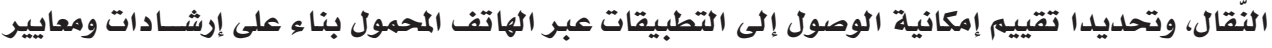

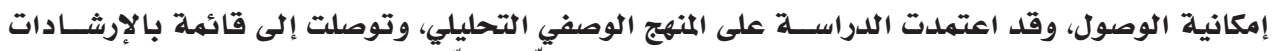

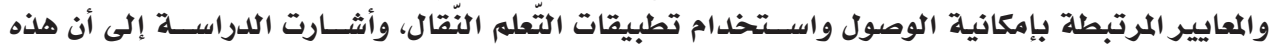

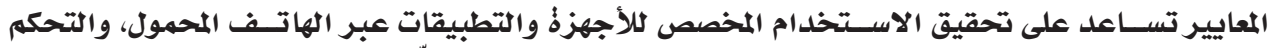

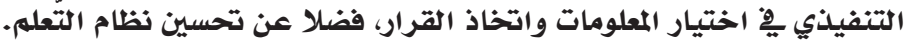


وِِِ نفس الســياق هدفت دراســة قرقاجي (2020) إلى تصميم تطبيق إلكتروني قائم على التّعلم النّقال

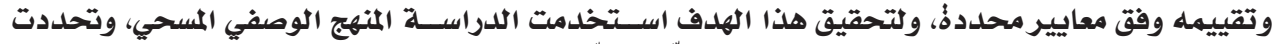

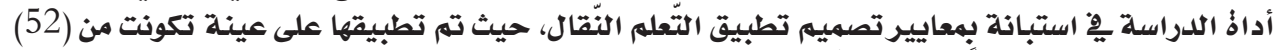

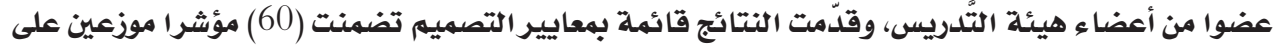

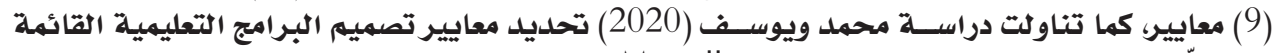

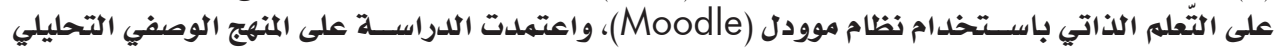

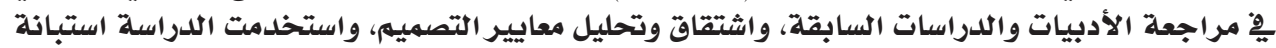

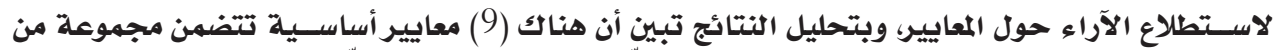

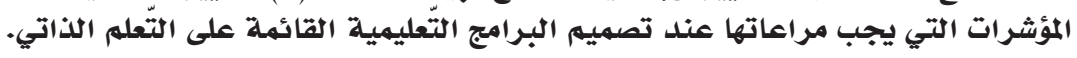

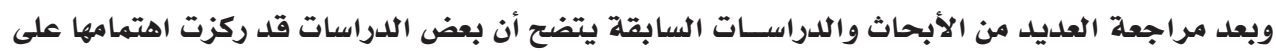

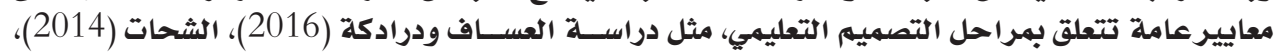

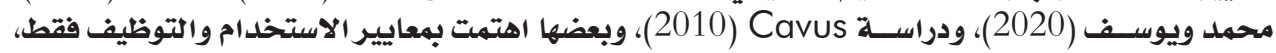

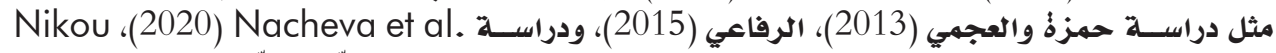

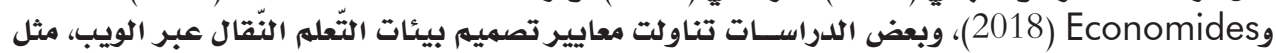

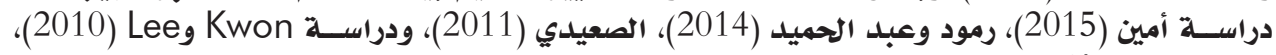

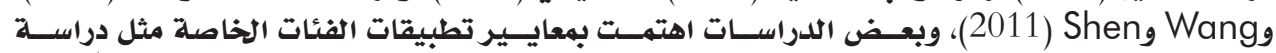

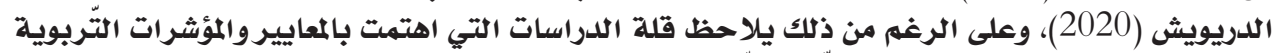

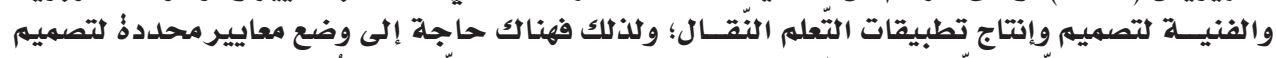

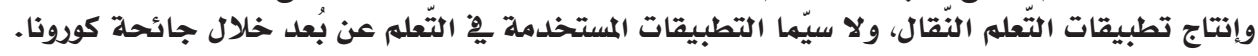
منهجية الدراسة وإجراءاتها: منهج الدراسة :

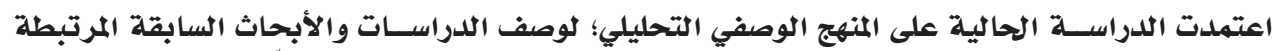

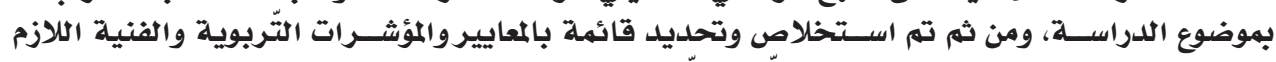
توافرها عند تصميه برامج وتطبيقات التّعله النّقال.

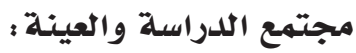

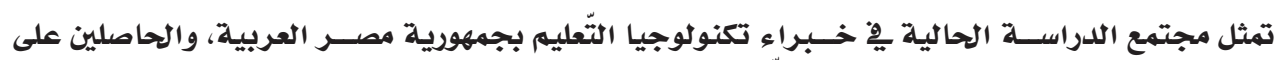

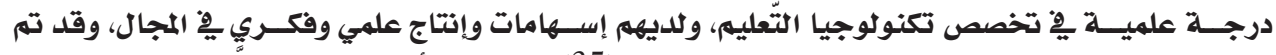

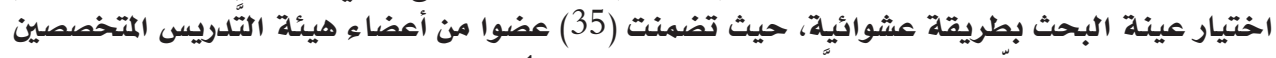

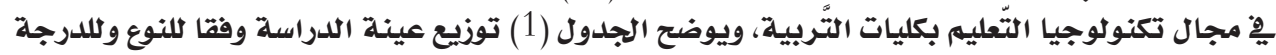

جدول (1): توزيع عينة البحث

\begin{tabular}{|c|c|c|c|}
\hline النسبة & التكرار & الفئة & المتغير \\
\hline$\% 62.85$ & 22 & ذكر & النوع \\
\hline$\% 37.14$ & 13 & أنثى & \\
\hline$\% 45.71$ & 16 & أستاذ أ & الدرجة العلمية \\
\hline$\% 37.14$ & 13 & أستاذ مساعد & \\
\hline$\% 17.14$ & 6 & مدرس & \\
\hline$\% 100$ & 35 & & \\
\hline
\end{tabular}




\section{أحمد محمد المباريدي}

المجلد الرابع عشر العدد (48) 2021م محمد المياريلم

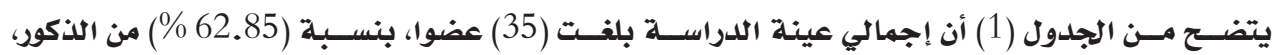

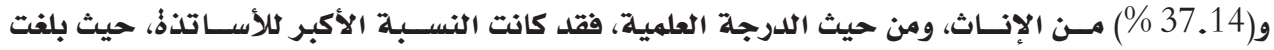

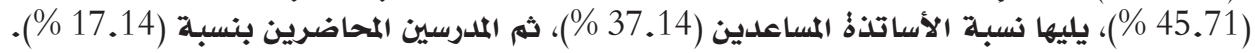
ويوضح الشكل (1) تخطيطا بيانيا لتوزيع عينة الدراسة ؛

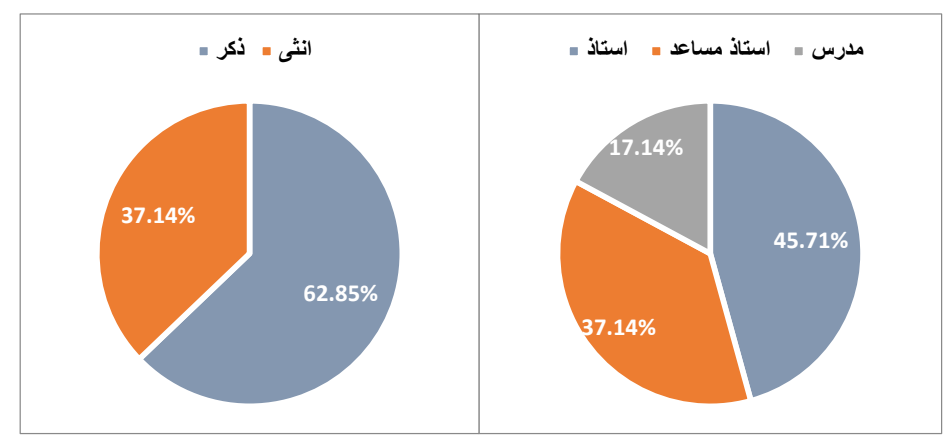

شكل (1): تخطيط بياني لتوزيع عينة الدراسة وفقا للنوع وللدرجة العلمية

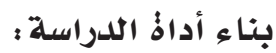

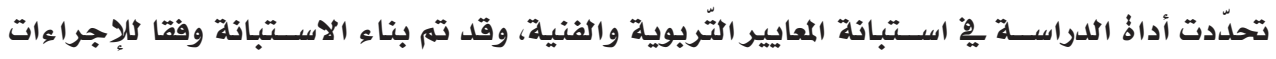
الآتية :

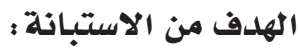

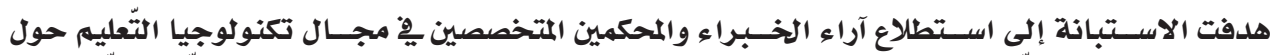

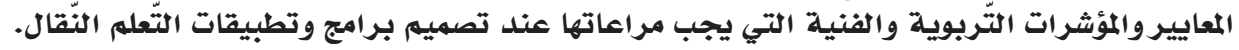

$$
\text { إعداد مجالات وبنود الاستبانة : }
$$

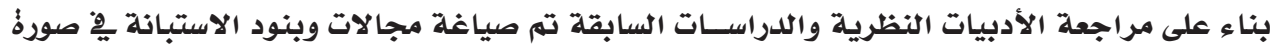

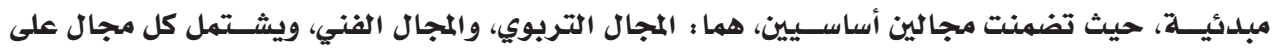

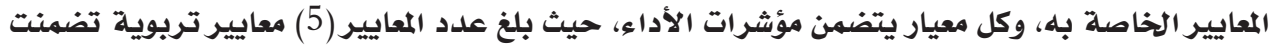

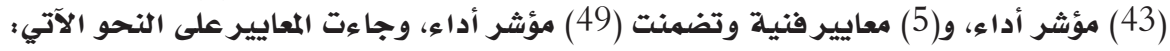

$$
\begin{aligned}
& \text { أولا: مجال المعايير التّربوية } \\
& \text { > تصميم الأهداف. } \\
& \text { > > > تصميم المحتوى. } \\
& \text { > > > تصميم الأنشطة. } \\
& \text { > > مصادر التّعلم. } \\
& \text { > >صميم أساليب التقويء. } \\
& \text { ثانيا : مجال المعايير الفنية } \\
& \text { > تصميه الواجهة الرئيسة. } \\
& \text { > > > >ميم شاشات التطبيق. } \\
& \text { > > >صميه عناصر الوسائط المتعلددة. } \\
& \text { > > > آمميم الإبحار والتفاعل. }
\end{aligned}
$$

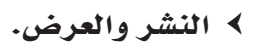


وقد تم مراعاذٌ أن تكون عبارات وبنود الاستبانة واضحة ودقيقة، وأن تكون منظمة تنظيما منطقيا، وأن تكون العبارات الفرعية مرتبطة بالمجالات الرئيسة.

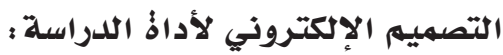

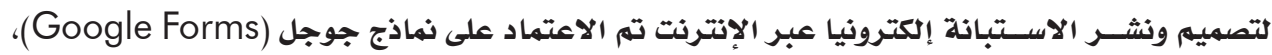

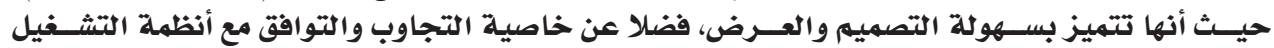

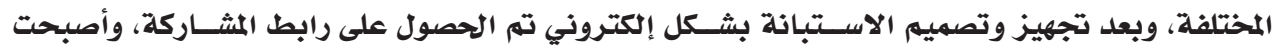

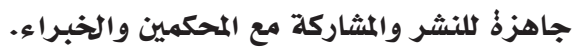

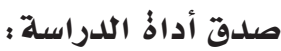

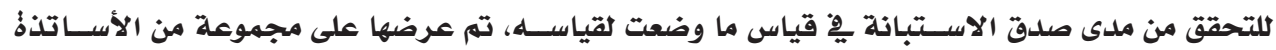

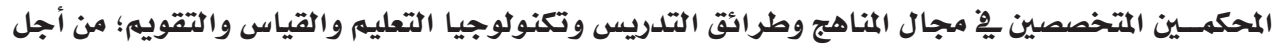

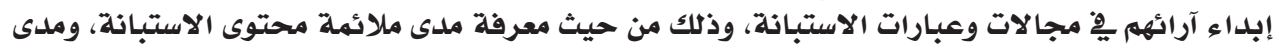

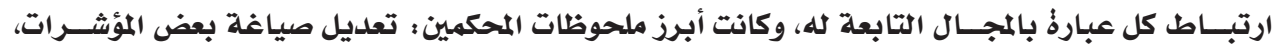
وإعادةٌ ترتيب بعض المعايير والمؤشرات بشكل منطقي.

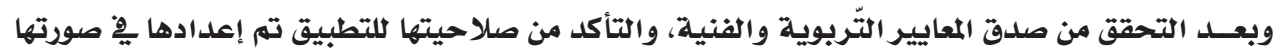

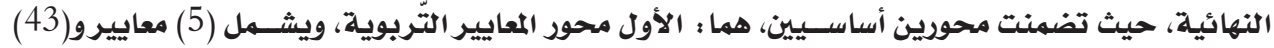

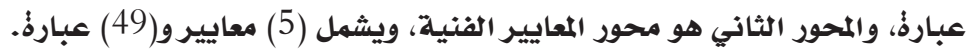

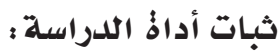

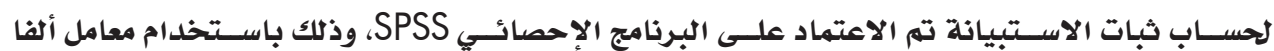

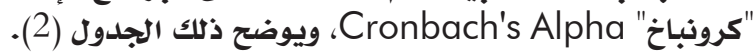
جدول (2) : معامل ألفا كرونباخ لثبات أداذٌ الدراسة

\begin{tabular}{|c|c|}
\hline معامل الثبات (ألفاكرونباخ) & محاور الاستبانة \\
\hline 0.90 & المعايير التربوية \\
\hline 0.917 & المعايير الفنية \\
\hline 0.91 & الثبات الكلي للاستبانة \\
\hline
\end{tabular}

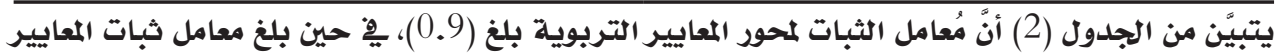

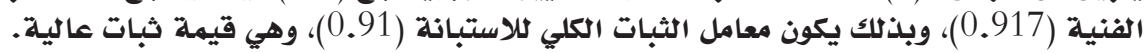

$$
\text { الأساليب الإحصائية : الإنهائ }
$$

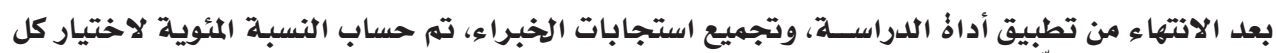

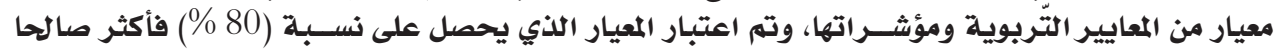

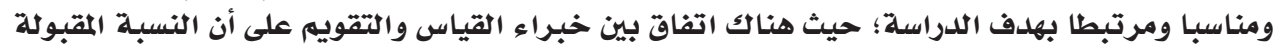

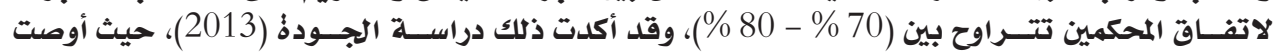

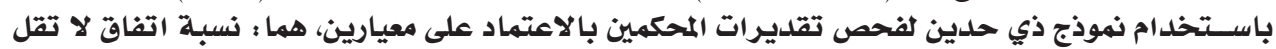

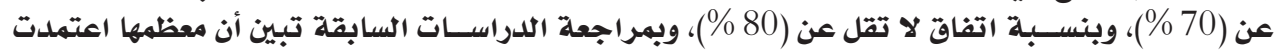
نسبة (80 \%)، مثل دراسة الصعيدي (2011)، وقدة اتفرقاجي (2020)، ومحمد ويوسف (2020). نتائج الدراسة ومناقشة الإنتها:

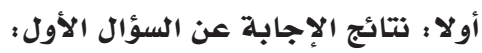

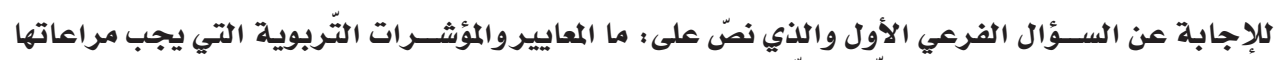

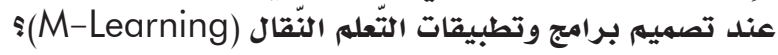




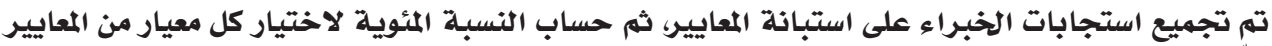

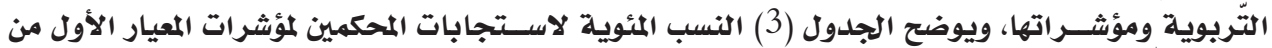

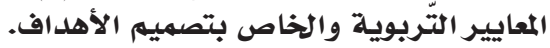

جدول (3) : النسب المئوية لاستجابات المحكمين لمؤشرات معيار تصميم الأهداف

\begin{tabular}{|c|c|c|c|}
\hline غير مناسب & 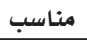 & المؤشرات & م \\
\hline$\% 0$ & $\% 100$ & معيار تصميم الأهداف & \\
\hline$\% 12$ & $\% 88$ & يُوضح الهدف العام من التطبيق. & 1 \\
\hline$\% 0$ & $\% 100$ & يُحدد الأهداف السلوكية. & 2 \\
\hline$\% 0$ & $\% 100$ & يصوغ الأهداف السلوكية صياغة قابلة للملاحظة والقياس. & 3 \\
\hline$\% 0$ & $\% 100$ & يُنوع الأهداف التعليمية. & 4 \\
\hline$\% 0$ & $\% 100$ & يصف الهدف سلوك المتعلم وليس سلوك المعلم. & 5 \\
\hline$\% 12$ & $\% 88$ & يُراعي شمول الأهداف لجميع المجالات والمستويات المختلفة. & 6 \\
\hline$\% 0$ & $\% 100$ & يُنظم الأهداف من المستويات الدنيا إلى المستويات العليا. & 7 \\
\hline
\end{tabular}

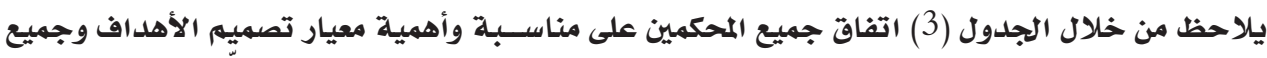

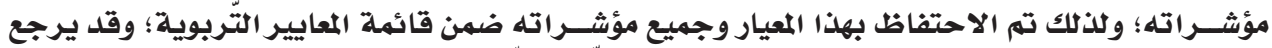

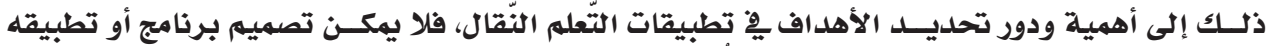

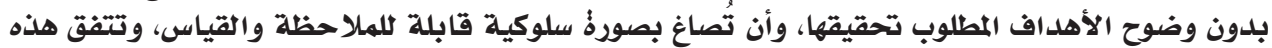

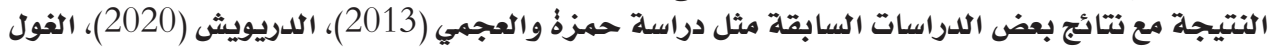

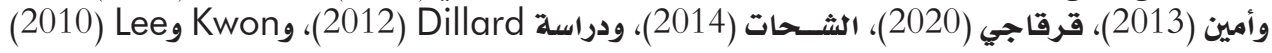

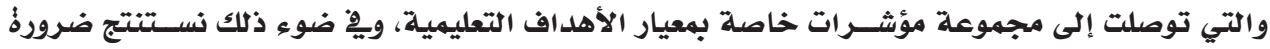
مراعاذٌ مؤشرات معيار الأهداف التعليمية ووضعها موضع الاعتبار أثناء تصميهم وتطوير تطبيقات التعلم

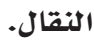

ويوضح الجلدول (4) النسب المئوية لاستجابات المحكمين لمؤشرات معيار تصميم المحتوى.

جدول (4) : النسب المئوية لاستجابات المحكمين لمؤشرات معيار تصميه المحتوى

\begin{tabular}{|c|c|c|c|}
\hline غير مناسب & 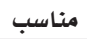 & المؤشرات & م \\
\hline$\% 0$ & $\% 100$ & معيار تصميم المحتوى & \\
\hline$\% 0$ & $\% 100$ & يتناسب محتوى التطبيق مع الفئة المستهدفة. & 8 \\
\hline$\% 0$ & $\% 100$ & يرتبط المحتوى بأهداف التطبيق. & 9 \\
\hline$\% 0$ & $\% 100$ & يُقسم المحتوى إلى موديولات أو دروس. & 10 \\
\hline$\% 0$ & $\% 100$ & يُنوع ِِِ طرق عرض المحتوى لمراعاذٌ الفروق الفردية بين المتعلمين. & 11 \\
\hline$\% 0$ & $\% 100$ & يعرض المادة العلمية بترتيب منطقي. & 12 \\
\hline$\% 0$ & $\% 100$ & يتضمن المحتوى مفردات واضحة ومألوفة. & 13 \\
\hline$\% 0$ & $\% 100$ & يُقدم محتوى صحيحا من الناحية العلمية. & 14 \\
\hline$\% 0$ & $\% 100$ & يخلو المحتوى من الأخطاء اللغوية. & 15 \\
\hline$\% 0$ & $\% 100$ & يُراعي حداثة المحتوى. & 16 \\
\hline$\% 0$ & $\% 100$ & يبنى المحتوى ِِِ ضوء نظرية تربوية واضحة. & 17 \\
\hline$\% 20$ & $\% 80$ & يدعم المحتوى المواقف الحياتية للمتعلمين. & 18 \\
\hline$\% 12$ & $\% 88$ & يتناسب المحتوى مع أنظمة وأجهزةٌ التّعلم النَقال. & 19 \\
\hline
\end{tabular}

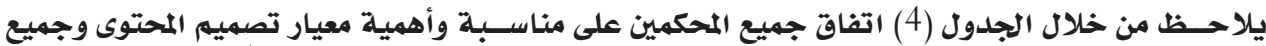

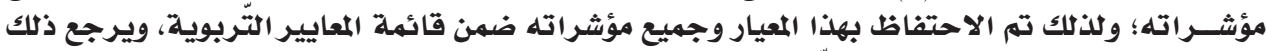

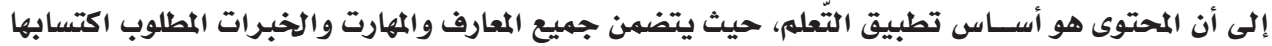


لدى المتعلمين، وتتفق هذه النتيجة مع نتائج دراســة الجهني (2014)، حجازي وآخرون (2020)، العسـاف وداف

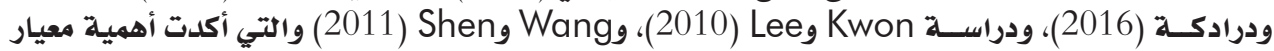
المحتوى ومؤشراته، وضرورةٌ وضعها موضع الاعتبار عند تصميم وتطوير برامج وتطبيقات التعله النقال.

ويوضح الجدول (5) النسب المئويلة لاستجابات الخبراء لمؤشرات معيار تصميم الأنثطة.

جدول (5) : النسب المئوية لاستجابات الخبراء لمؤشرات معيار تصميه الأنشطة

\begin{tabular}{|c|c|c|c|}
\hline غير مناسب & 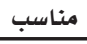 & المؤشرات & $\hat{\imath}$ \\
\hline$\% 0$ & $\% 100$ & معيار تصميم الأنشطة & \\
\hline$\% 0$ & $\% 100$ & يربط الأنشطة بالمحتوى. & 20 \\
\hline$\% 0$ & $\% 100$ & تسهم الأنشطة يِّ تحقيق الأهداف. & 21 \\
\hline$\% 0$ & $\% 100$ & يُوظف الأنشطة بشكل يجذب المتعلم ويشجعه على الأداء. & 22 \\
\hline$\% 0$ & $\% 100$ & تتضمن الأنشطة إرشادات واضحة. & 23 \\
\hline$\% 20$ & $\% 80$ & تتدرج الأنشطة من السهل إلى الصعب ومن المحسوس إلى المجرد. & 24 \\
\hline$\% 0$ & $\% 100$ & تناسب الأنشطة خصائص المتعلمين واحتياجاتهم. & 25 \\
\hline$\% 0$ & $\% 100$ & تُسهم الأنشطة يْ تنمية المهارات لدى المتعلمين. & 26 \\
\hline$\% 12$ & $\% 88$ & تُسهم الأنشطة ِِْ بناء المعرفة لدى المتعلمين. & 27 \\
\hline
\end{tabular}

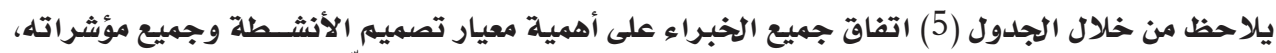

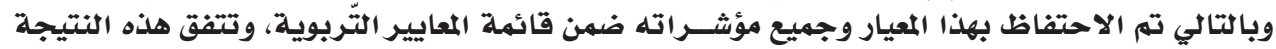

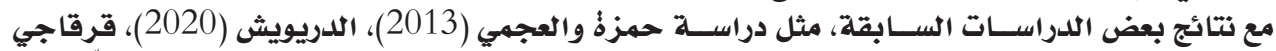

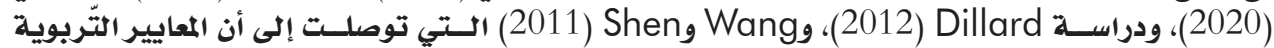

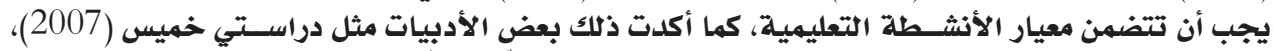

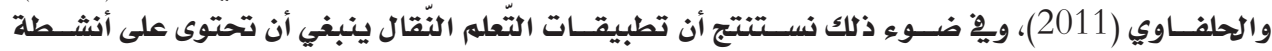

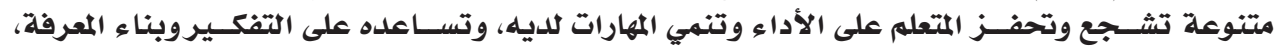

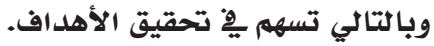

ويوضح الجدول (6) النسب المئوية لاستجابات الخبراء لمؤشرات معيار مصادر التّعلم. جدول (6) : النسب المئوية لاستجابات الخبراء لمؤشرات معيار مصادر التّعلم

\begin{tabular}{|c|c|c|c|}
\hline غير مناسب & 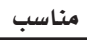 & المؤشرات & م \\
\hline$\% 0$ & $\% 100$ & معيار مصادر التّعلم & \\
\hline$\% 0$ & $\% 100$ & يُنوع مصادر التّعلم. & 28 \\
\hline$\% 0$ & $\% 100$ & ترتبط مصادر التّعلم بالأهداف المرجو تحقيقها. & 29 \\
\hline$\% 0$ & $\% 100$ & تتكامل مصادر التّعلم مع المحتوى. & 30 \\
\hline$\% 0$ & $\% 100$ & يُسهل الوصول إلى مصادر التَعلم. & 31 \\
\hline$\% 0$ & $\% 100$ & تتناسب مصادر التّعلم مع الفئة المستهدفة. & 32 \\
\hline$\% 0$ & $\% 100$ & يتضمن روابط إنترنت تثري التّعله. & 33 \\
\hline
\end{tabular}

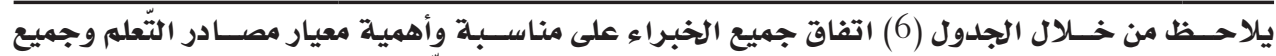

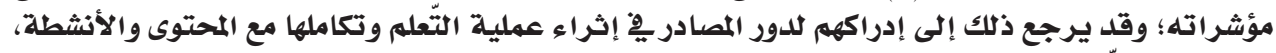

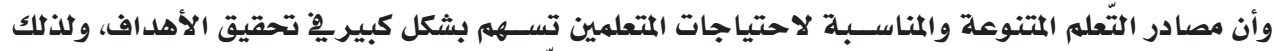

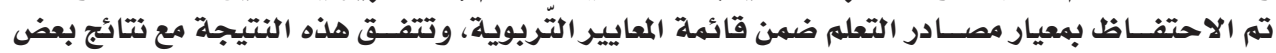

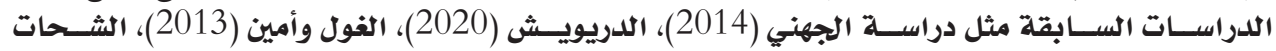

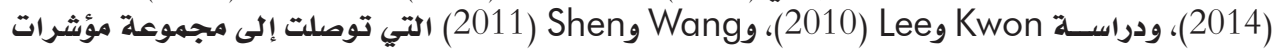

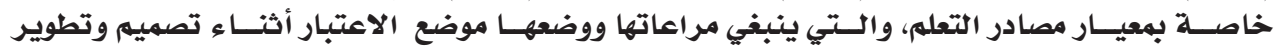
تطبيقات التعله النقال. 


$$
\text { المجلد الرابع عشر العدد (48) 2021م المباريدي }
$$

ويوضح الجلدول (7) النسب المئويـة لاستجابات المحكمين لمؤشرات معيار أساليب التقويم.

\begin{tabular}{|c|c|c|c|}
\hline غير مناسب & 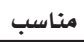 & المؤشرات & a \\
\hline$\% 0$ & $\% 100$ & معيار أساليب التقويم & \\
\hline$\% 0$ & $\% 100$ & يربط التقويم بالأهداف ويقيس مدى تحققها. & 34 \\
\hline$\% 12$ & $\% 88$ & 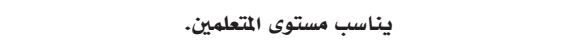 & 35 \\
\hline$\% 0$ & $\% 100$ & يُوفر تقويم بنائي مستمر. & 36 \\
\hline$\% 0$ & $\% 100$ & 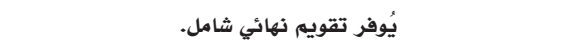 & 37 \\
\hline$\% 0$ & $\% 100$ & يُغطي التقويم جميع جوانب المحتوى. & 38 \\
\hline$\% 0$ & $\% 100$ & يُمكن المتعلمين من التعرف على مدى تقدمهم ونتائجهم. & 39 \\
\hline$\% 0$ & $\% 100$ & يُنوع أسئلة التقويم. & 40 \\
\hline$\% 12$ & $\% 88$ & يُوفر تغذية راجعة للمتعلمين. & 41 \\
\hline$\% 0$ & $\% 100$ & تتصف الاختبارات بالموضوعية والصدق. & 42 \\
\hline$\% 0$ & $\% 100$ & تتوافق أساليب التقويم مع أنظمة التسليم والنشر للتعلم النّقال. & 43 \\
\hline
\end{tabular}
جدول (7) : النسب المئوية لاستجابات المحكمين لمؤشرات معيار أساليب التقويم

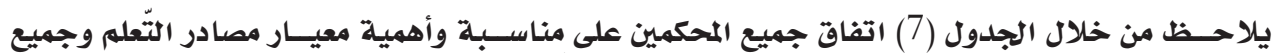

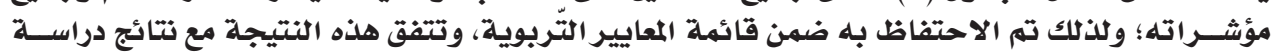

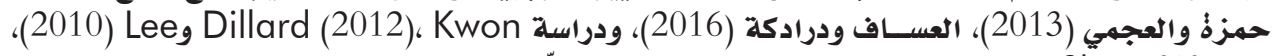

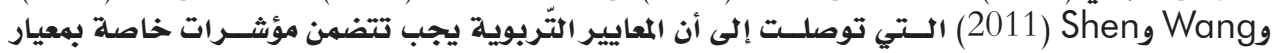

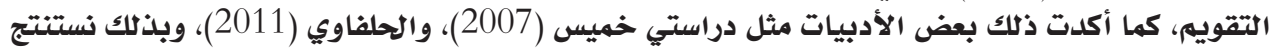

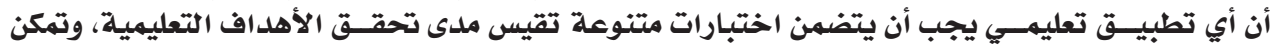

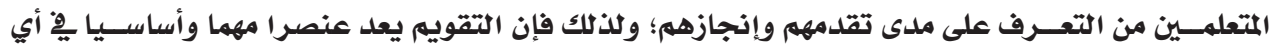
تطبيق تعليمي. ملخص نتائج الإجابة عن السؤال الأول : أثـارت نتائج الإجابة عن السؤال الأول إلى اتفاق أكثر من (80 \%) من الخبه الخبراء على على أهمية جميع معايير

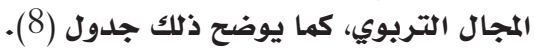

\begin{tabular}{|c|c|c|c|}
\hline غير مناسب & مناسب & المعايير التربوية & م \\
\hline$\% 0$ & $\% 100$ & معيار تصميم الأهداف & 1 \\
\hline$\% 0$ & $\% 100$ & معيار تصميم المحتوى & 2 \\
\hline$\% 0$ & $\% 100$ & معيار تصميم الأنشطة & 3 \\
\hline$\% 0$ & $\% 100$ & معيار مصادر التّعلم & 4 \\
\hline$\% 0$ & $\% 100$ & معيار أساليب التقويم & 5 \\
\hline
\end{tabular}
جدول (8) : ملخص استجابات الخبراء لمعايير المجال التربوي

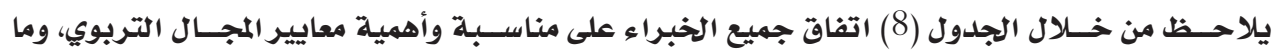

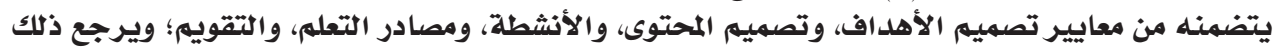

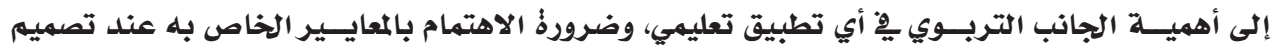

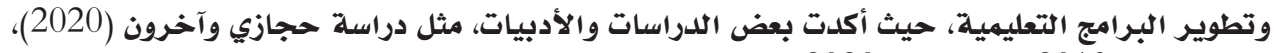

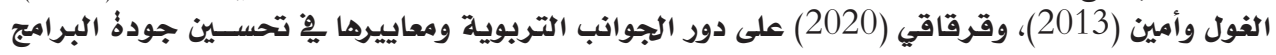


ثانيا : نتائج الإجابة عن السؤال الثاني:

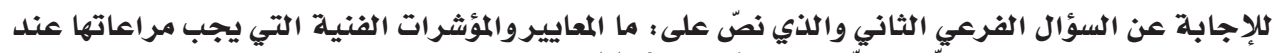

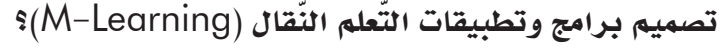

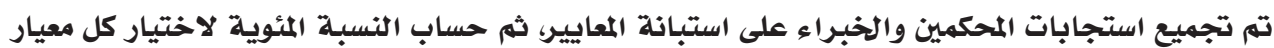

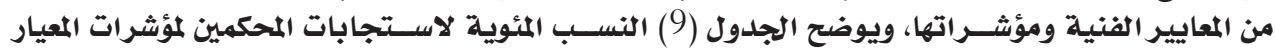

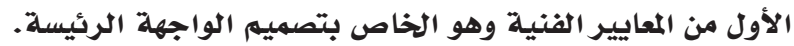

جلدول (9): النسب المئوية لاستجابات المحكمين لمؤشرات معيار تصميه الواجهة الرئيسة

\begin{tabular}{|c|c|c|c|}
\hline 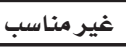 & 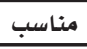 & المؤشرات & s \\
\hline$\% 0$ & $\% 100$ & معيار تصميم الواجهة الرئيسة & \\
\hline$\% 0$ & $\% 100$ & يعرض الشاشة الرئيسة بأسلوب مشوق وجذاب. & 1 \\
\hline$\% 0$ & $\% 100$ & يُحدد العنوان الرئيسي بوضوح. & 2 \\
\hline$\% 0$ & $\% 100$ & تتميز الواجهة الرئيسة بالبساطة وعدم التعقيد. & 3 \\
\hline$\% 0$ & $\% 100$ & يُوضح القائمة الرئيسة والقوائم الفرعية. & 4 \\
\hline$\% 0$ & $\% 100$ & يُوزع العناصر ٍِِ الشاشة بأسلوب منطقي ومناسب. & 5 \\
\hline$\% 20$ & $\% 80$ & تتناسب الواجهة الرئيسة مع خصائص المتعلمين. & 6 \\
\hline$\% 12$ & $\% 88$ & تتضمن شعار أو صور واقعية تعبر عن موضوع التطبيق. & 7 \\
\hline
\end{tabular}

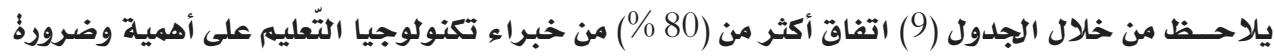

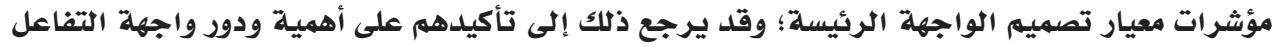

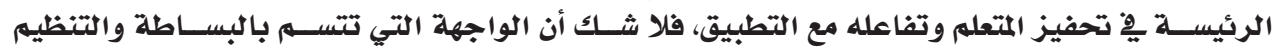

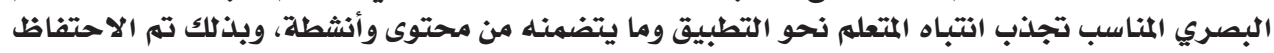

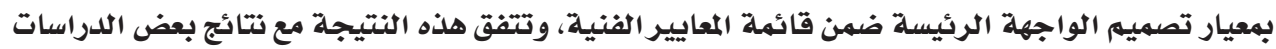

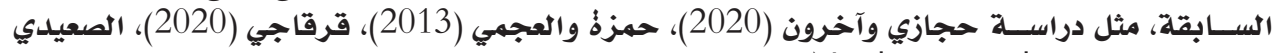

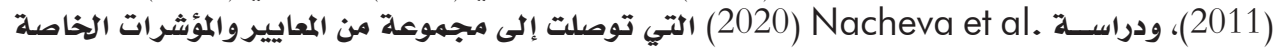
بتصميم صفحات وواجهات التفاعل ضمن برامج التعلم النقال.

ويبين الجدول (10) النسب المئوية لاستجابات الخبراء لمؤشرات معيار تصميم شاشات التطبيق. جلدول (10): النسب المئوية لاستجابات الخبراء لمؤشرات معيار تصميم شاشات التطبيق

\begin{tabular}{|c|c|c|c|}
\hline غير مناسب & 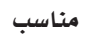 & المؤشرات & م \\
\hline$\% 0$ & $\% 100$ & معيار تصميه شاشات التطبيق & \\
\hline$\% 12$ & $\% 88$ & يعرض شاشة الأهداف يفِ البداية. & 8 \\
\hline$\% 0$ & $\% 100$ & تتناول كل شاشة مفهوما أو فكرةٌ واحدة. & 9 \\
\hline$\% 0$ & $\% 100$ & يربط بين الشاشات بشكل منطقي وتفاعلي. & 10 \\
\hline$\% 0$ & $\% 100$ & يُوظف خلفيات مناسبة ومريحة للعين. & 11 \\
\hline$\% 0$ & $\% 100$ & تباين ألوان الخلفيات مع محتويات الشاشات. & 12 \\
\hline$\% 0$ & $\% 100$ & يُنظم الصفحات تنظيما بصريا دقيقا ومتناسقا. & 13 \\
\hline$\% 0$ & $\% 100$ & يتجنب كثرةٌ التفاصيل وازدحام الشاشات. & 14 \\
\hline$\% 0$ & $\% 100$ & يتوافر الاتزان الشكلي ِِّ تصميم جميع الشاشات. & 15 \\
\hline$\% 0$ & $\% 100$ & يتناسب تخطيط الشاشات مع أدوات النشر والتسليه. & 16 \\
\hline
\end{tabular}

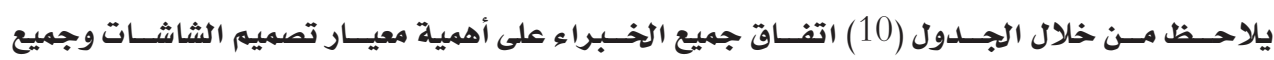

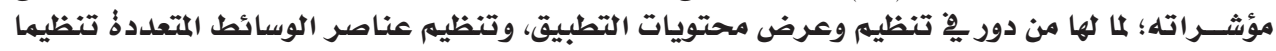

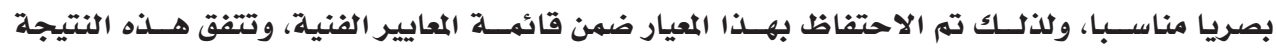




$$
\text { المجلد الرابع عشر العدد (48) 2021م أحمد المباريدي }
$$

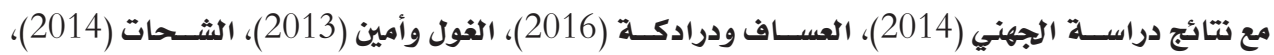

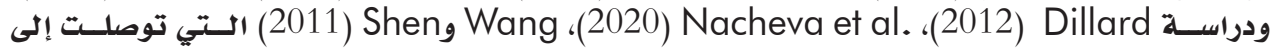

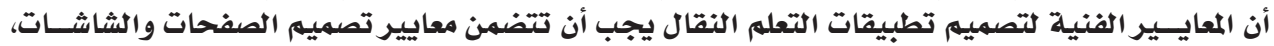

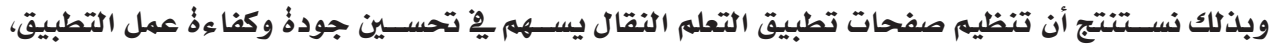

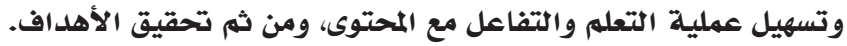

ويبين الجدول (11) نسب استجابات المحكمين لمؤشرات معيار تصميم عناصر الوسائط المتعددة.

\begin{tabular}{|c|c|c|c|}
\hline غير مناسب & 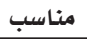 & المؤشرات & $\hat{r}$ \\
\hline$\% 0$ & $\% 100$ & معيار تصميه عناصر الوسائط المتعددذ؛ & \\
\hline$\% 0$ & $\% 100$ & يعرض نصوصا واضحة ومناسبة من حيث الحجم والنوع. & 17 \\
\hline$\% 0$ & $\% 100$ & يُنسق العناوين الرئيسة والفقرات تنسيقا مناسبا. & 18 \\
\hline$\% 0$ & $\% 100$ & يعرض تسجيلات صوتية واضحة. & 19 \\
\hline$\% 0$ & $\% 100$ & يُحقق الصوت الهدف من توظيفه داخل التطبيق. & 20 \\
\hline$\% 0$ & $\% 100$ & يخلو التسجيل الصوتي من أي مؤثرات غير مرغوب فيها. & 21 \\
\hline$\% 0$ & $\% 100$ & يستخدم صورا تعليمية ذات جودةٌ عالية. & 22 \\
\hline$\% 0$ & $\% 100$ & يُراعي استخدام الصور الأكثر واقعية. & 23 \\
\hline$\% 0$ & $\% 100$ & يستخدم لقطات فيديو بجودة عالية. & 24 \\
\hline$\% 0$ & $\% 100$ & ترتبط مقاطع الفيديو بمحتويات التطبيق. & 25 \\
\hline$\% 12$ & $\% 88$ & يستخدم مقاطع فيديو ذات مدةٌ زمنية قصيرذٌ. & 26 \\
\hline$\% 0$ & $\% 100$ & تتناسب الوسائط مع الفئة المستهدفة. & 27 \\
\hline$\% 0$ & $\% 100$ & يمكن تحكم المتعلم هٍِ تشغيل الوسائط. & 28 \\
\hline$\% 35$ & $\% 75$ & يعرض الوسائط بالامتدادات المتوافقة مع الأجهزةٌ النَقالة. & 29 \\
\hline$\% 0$ & $\% 100$ & تتوافق الوسائط المتعددذٌ من أداوت النشر والتسليم. & 30 \\
\hline
\end{tabular}
جدول (11) : النسب المئوية لاستجابات المحكمين لمؤشرات معيار تصميم عناصر الوسائط المتعددذ؛

يلاحظ من خلال الجلدول (11) اتفاق جميع المحكمين على أهمية معيار تصميه عناصر الوسائط المتعلدد؛

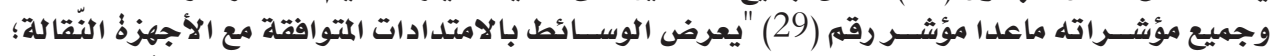

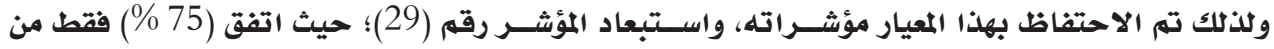

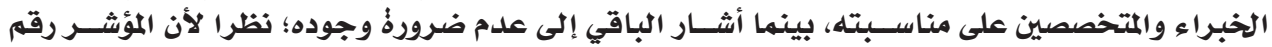

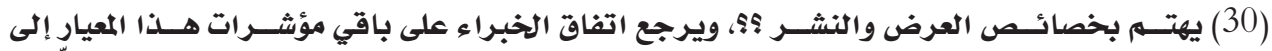

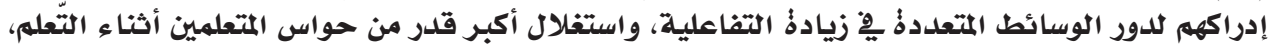

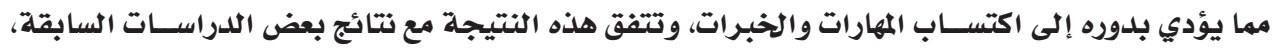

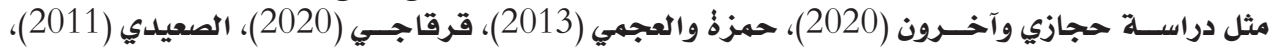
الوسان Nacheva et al. الوسائط المتعددة. ويبين الجدول (12) التالي نسب استجابات الخبراء لمؤشرات معيار الإبحار والتفاعل.

\begin{tabular}{|c|c|c|c|}
\hline غير مناسب & 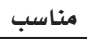 & المؤشرات & م \\
\hline$\% 0$ & $\% 100$ & معيار الإبحار والتفاعل & \\
\hline$\% 0$ & $\% 100$ & يُوفر قائمة رئيسة للانتقال إلى أي مكان داخل التطبيق. & 31 \\
\hline$\% 0$ & $\% 100$ & يُمكن الرجوع إلى القائمة الرئيسة من أي مكان ٍِِ التطبيق. & 32 \\
\hline$\% 0$ & $\% 100$ & يُمكن الاتصال بشبكة الإنترنت من داخل التطبيق. & 33 \\
\hline$\% 0$ & $\% 100$ & يتضمن قائمة بالمفضلات Favorites. & 34 \\
\hline
\end{tabular}
جدول (12) : النسب المئوية لاستجابات الخبراء لمؤشرات معيار الإبحار والتفاعل 
جدول (12) : يتبع

\begin{tabular}{|c|c|c|c|}
\hline غير مناسب & 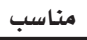 & المؤشرات & r \\
\hline$\% 12$ & $\% 88$ & يُتيح أخذ مذكرات نصية ومرئية أثناء التصفح. & 35 \\
\hline$\% 0$ & $\% 100$ & تخلو الروابط Links من الأخطاء التقنية. & 36 \\
\hline$\% 0$ & $\% 100$ & يستخدم رموزا وأيقونات واضحة ومعبرة & 37 \\
\hline$\% 0$ & $\% 100$ & يُراعي سهولة الانتقال بين الصفحات. & 38 \\
\hline$\% 0$ & $\% 100$ & يُوفر إمكانية تكبير Zoom الأجزاء المهمة. & 39 \\
\hline$\% 0$ & $\% 100$ & يُمكن الخروج من التطبيق ِِّ أي وقت. & 40 \\
\hline
\end{tabular}

يلاحظ من خلال الجلدول (12) اتفاق جميع الخبراء على أهمية معيار الإبحار والتفاعل وجميع مؤشراته؛

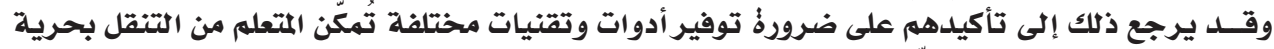

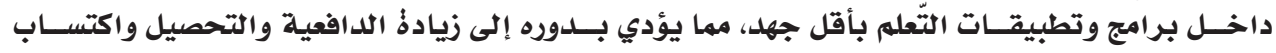

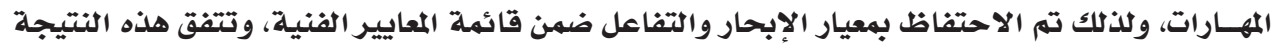

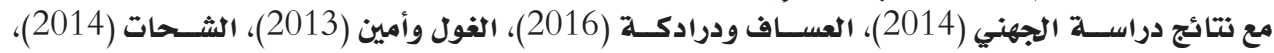

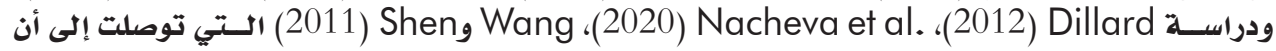
المعايير الفنية لتصميم تطبيقات التعله النقال يجب أن تتضمن معايير تصميم الإبحار والتفاعل. ويبين الجلدول (13) نسب استجابات المحكمين لمؤشرات معيار النشر والعرض. جدول (13): النسب المئوية لاستجابات المحكمين لمؤشرات معيار النشر والعرض

\begin{tabular}{|c|c|c|c|}
\hline غير مناسب & مناسب & المؤشرات & ค \\
\hline$\% 0$ & $\% 100$ & معيار النشر والعرض & \\
\hline$\% 0$ & $\% 100$ & يلدعم معايير سكورم SCORM. & 41 \\
\hline$\% 0$ & $\% 100$ & يتوافق عرض التطبيق من نظام الأندرويد Android. & 42 \\
\hline$\% 0$ & $\% 100$ & يسهل فتح وعرض التطبيق على أجهزةٌ التّعلم النَقال. & 43 \\
\hline$\% 12$ & $\% 88$ & يمكن نقل التطبيق من جهاز إلى آخر. & 44 \\
\hline$\% 0$ & $\% 100$ & يتوافق عرض وتصفح التطبيق مع اللغة المستخدمة. & 45 \\
\hline$\% 0$ & $\% 100$ & يسهل الوصول إلى المحتوى يِّ أي وقت ومن أي مكان. & 46 \\
\hline$\% 0$ & $\% 100$ & يتضمن بيانات المؤلف وحقوق النشر. & 47 \\
\hline$\% 12$ & $\% 88$ & يُمكن استخدام التطبيق بدون الاتصال بالإنترنت. & 48 \\
\hline$\% 0$ & $\% 100$ & يُمكن حذف التطبيق من الجهاز بسهولة. & 49 \\
\hline
\end{tabular}

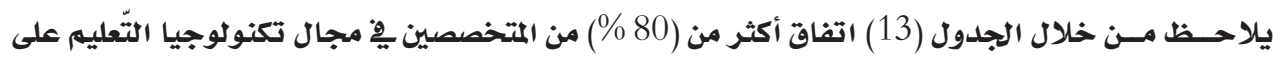

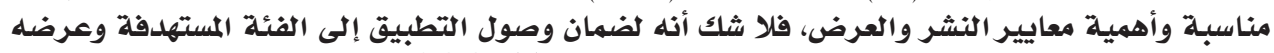

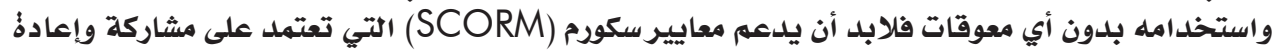

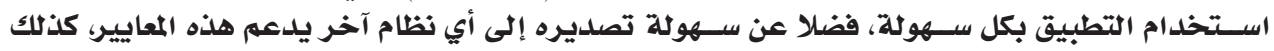

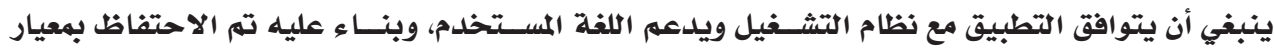

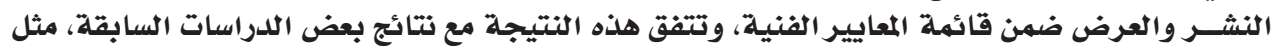

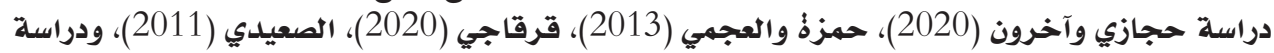
والوصول. Nacheva et al.

والوصول.

ملحص نتائج الإجابة عن السؤال الثاني:

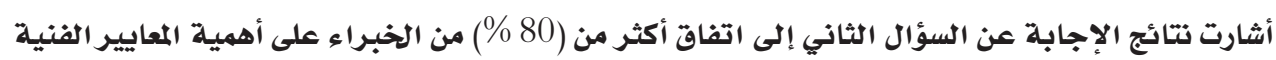
لتصميم تطبيقات التعلم النقال، كما يوضح ذئ ذلك الجدال الجدول (14). جوذة التعليم الجامعي 


$$
\begin{aligned}
& \text { أحمد محمد المباريدي } \\
& \text { المجلد الرابع عشر العدد (48) 2021م أحمد مياريدي }
\end{aligned}
$$

\begin{tabular}{|c|c|c|c|}
\hline غير مناسب & 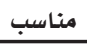 & المعايير الفنية & م \\
\hline$\% 0$ & $\% 100$ & تصميم الواجهة الرئيسة & 1 \\
\hline$\% 0$ & $\% 100$ & تصميم شاشات التطبيق & 2 \\
\hline$\% 0$ & $\% 100$ & تصميم عناصر الوسائط المتعددة: & 3 \\
\hline$\% 0$ & $\% 100$ & تصميه الإبحار والتفاعل & 4 \\
\hline$\% 0$ & $\% 100$ & النشر والعرض & 5 \\
\hline
\end{tabular}

جدول (14): ملخص استجابات الخبراء لمعايير المجال الفني

يـلاحظ من خلال الجلدول (14) اتفاق جميع الخبراء على مناسـبـة وأهمية المعايير الفنية للتصميم التي وائي

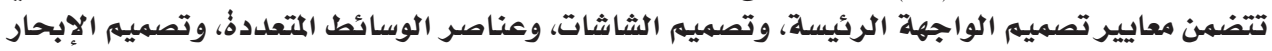

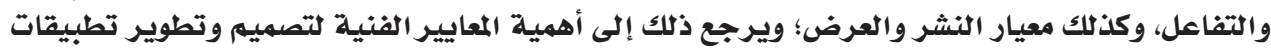

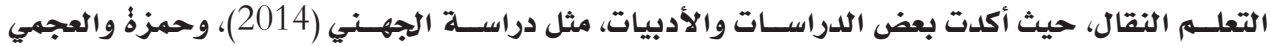

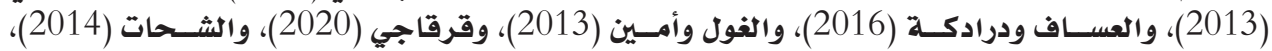

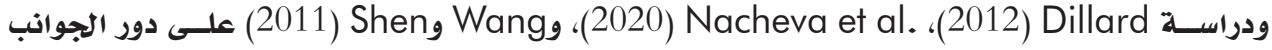
الفنية ومعاييرها ِِّ تحسين جودةٌ البرامج والتطبيقات التعليمية.

$$
\text { ملخص نتائج الدراسة: }
$$

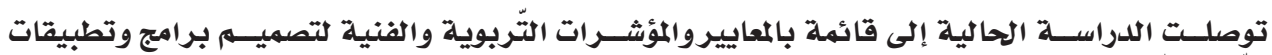

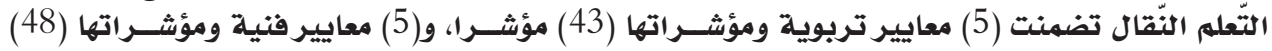

\begin{tabular}{|c|c|c|}
\hline عدد المؤشرات & المعايير & المجال \\
\hline 7 & تصميه الأهداف & المجال التربوي \\
\hline 12 & تصميم المحتوى & \\
\hline 8 & تصميم الأنشطة & \\
\hline 6 & مصادر التّعلم & \\
\hline 10 & أساليب التقويم & \\
\hline (43) مؤشر & (5) معايير تربوية & إجمالي \\
\hline 7 & تصميم الواجهة الرئيسة & المجال الفني \\
\hline 9 & تصميه شاشات التطبيق & \\
\hline 13 & تصميم عناصر الوسائط المتعددة: & \\
\hline 10 & تصميم الإبحار والتفاعل & \\
\hline 9 & النشر والعرض & \\
\hline (48) مؤشر & (5) معايير فنية & إجمالي \\
\hline
\end{tabular}

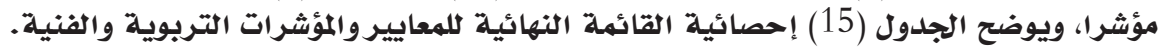
جدول (15): إحصائية القائمة النهائية للمعاييروالمؤشرات التّربوية والفنية الميله

الاستنتاجات:

مِّ ضوء تحليل نتائج الدراسة، ومناقشتها وتفسيرها، توصل الباحث إلى الاستنتاجات الآتية ؛

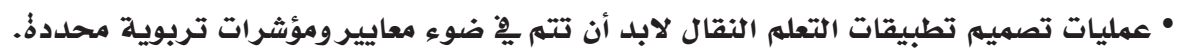

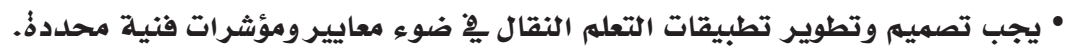

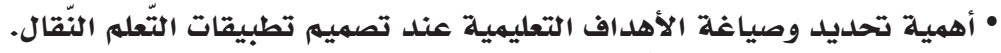

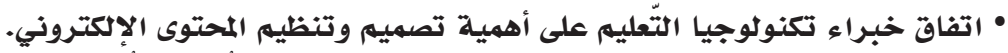

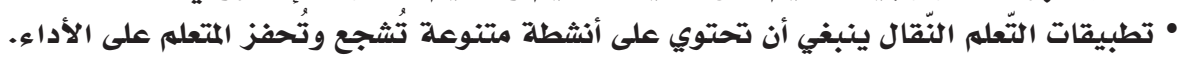


• تأكيد الخبراء على دور مصادر التّعلم هِ إثراء عملية التّعله، وأهمية تكاملها مع المحتوى والأنشطة.

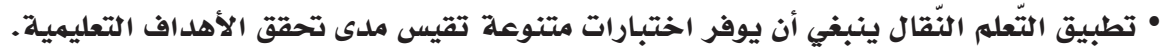

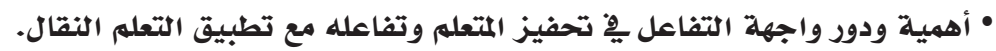

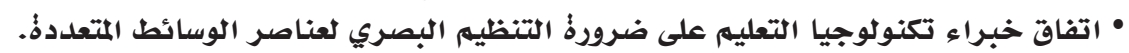

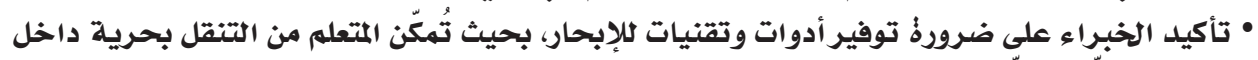

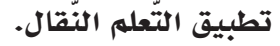

التوصيات:

هِّ ضوء النتائج التي تم التوصل إليها، وبناء على استنتاجات الدراسة يوصي الباحث بالآتي:

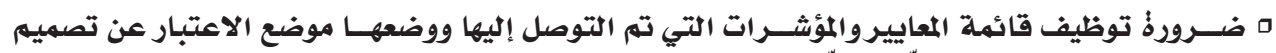
وإنتاج برامج وتطبيقات التّعلم النّقال.

ه الاهتمام بجودذٌ تصميه وإنتاج برامج التّعلم الإكتروني عامة، وتطبيقات التّعلم التّقال بصفةٍ خاصة.

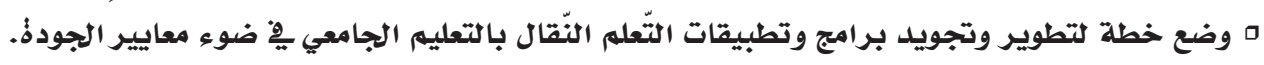
ه الاهتمام بتصميه وتنظيه المحتوى الإلكتروني عند تطوير تطبيقات التّعلم التّقال. ه مراعاذٌ توفير أنشطة تعليمية متنوعة تحفز وتشجع الطلاب على التّعله النّقال.

ه الاهتمام بلدعم تطبيقات التعلم النقال بالمصادر الإثرائية التي تتكامل مع المحتوى والأنشطة. ه عقد دورات تدريبية وورث عمل للمعلمين والطلاب للتعريف بالمعايير القومية والعالمية لتصميهم وتوظيف البرامج والتطبيقات التعليمية. البحوث المقترحة:

• إجراء بحوث لتحديل معايير الجوانب البنائية والتصميمية لتطبيقات التّعلم النّقال.

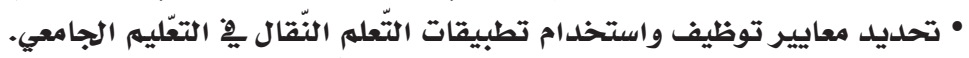

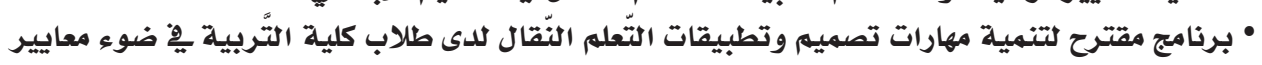
المودة.

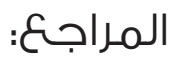
أمين، زينب محمد (2015). المســتحلثات التكنولوجية رؤى وتطبيقات. القاهرةٌ : المؤسســة العربية للعلوم والثقافة.

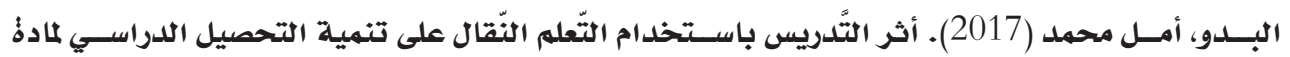

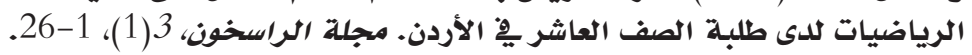

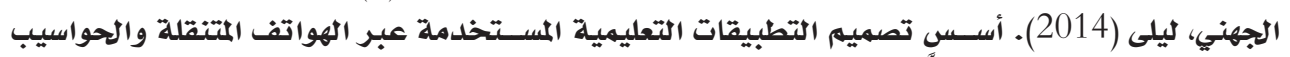

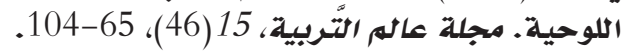

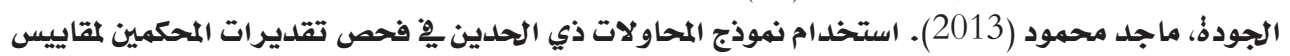

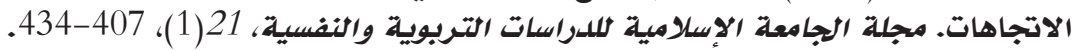

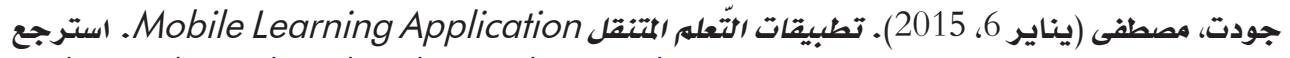
http://drgawdat.edutech-portal.net/archives/13600 من بوابة تكنولوجيا التعليه:

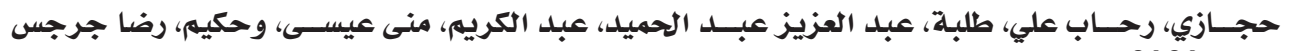

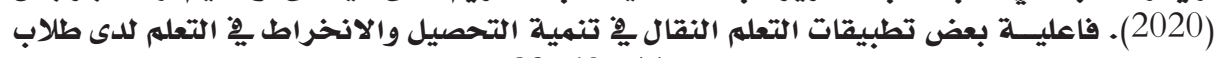

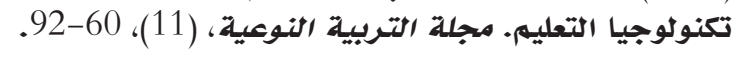


الحلفاوي، وليد سالم (2011). التعليه الإلكتروني تطبيقات مستحلثة. القاهرةٌ ؛ دار الفكر العربي.

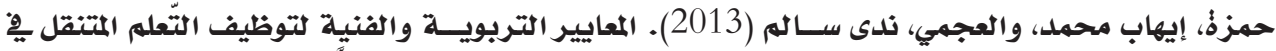
برامسج التدريب الإكتروني بلدولة الكويت. مجلة دراسـات عربية فِّ التّربية وعلمه النفس، 4 (43)، .51-1

خميس، محمد عطية (2007). الكهبيوتر التعليهي وتكنولوجيا الوســائط المتعلددة. القاهرةٌ ؛ دار السحاب

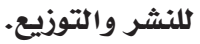
خميـس، محمد عطية (2011). الأصول النظربية والتاريخيـة لتكنولوجيا التعليه الإكتروني. القاهرةٌ :

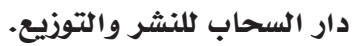

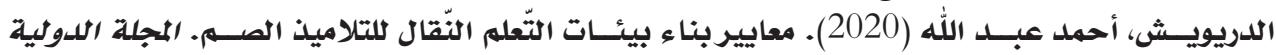

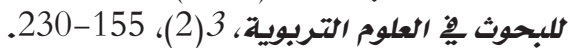

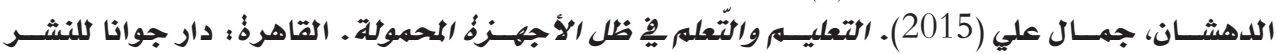
والتوزيع.

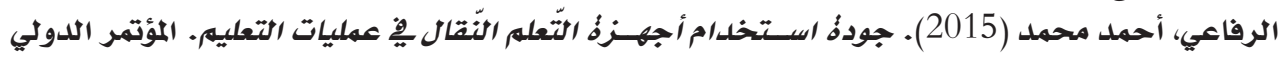

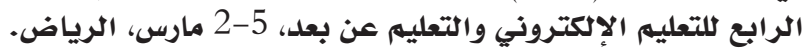

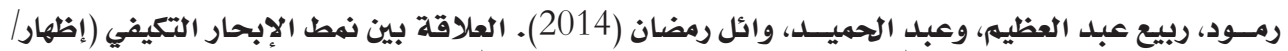

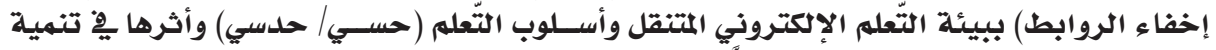

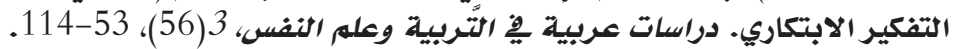

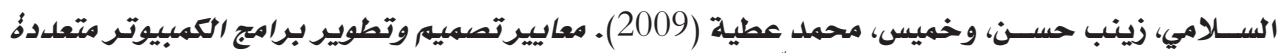

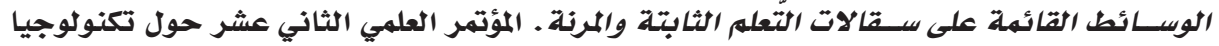

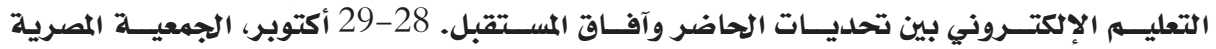

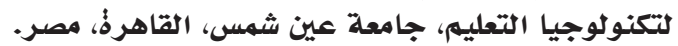

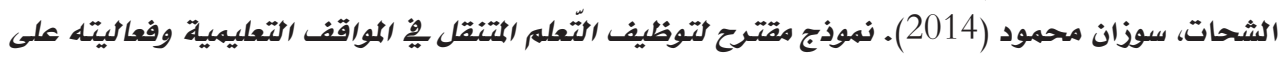

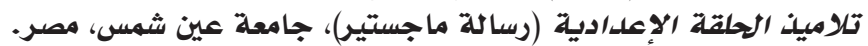

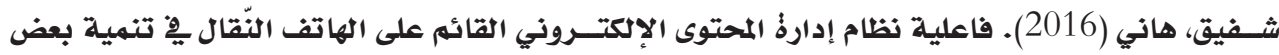

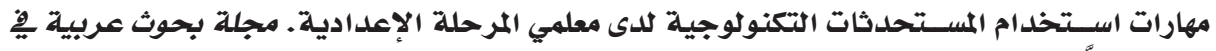

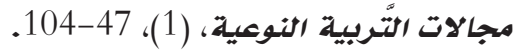

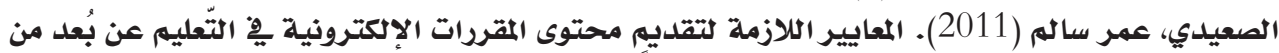

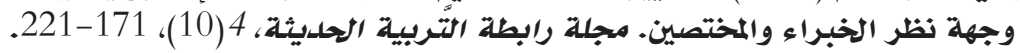

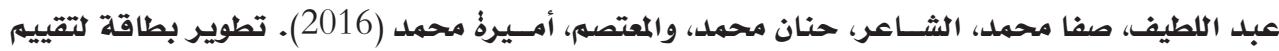

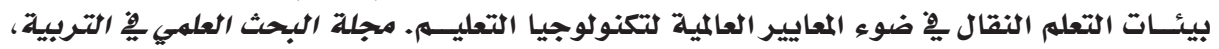
.237-203، (7)

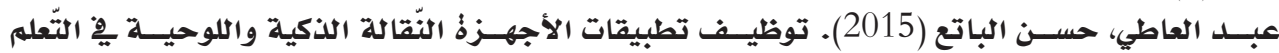

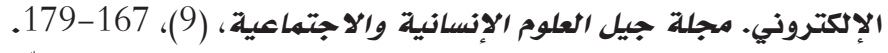

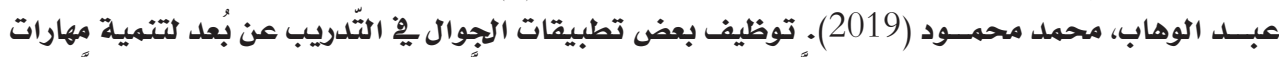

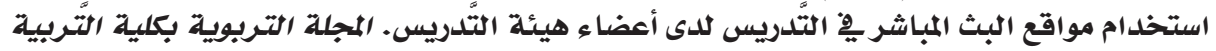

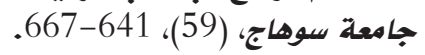

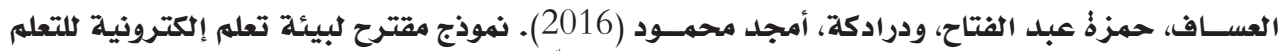

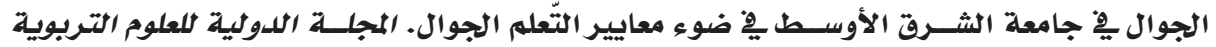

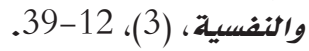




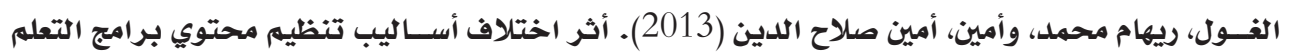

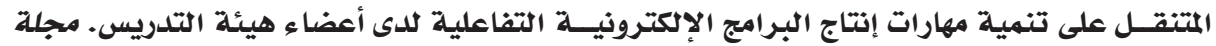

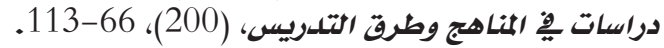

قرقاجي، أثــواق دحمان (2020). تصميم تطبيق إلكتروني قائم على التّعلم المتنقل وتقييمه وفق معايير

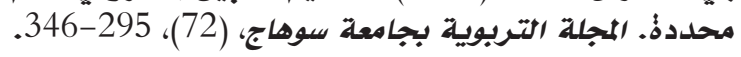

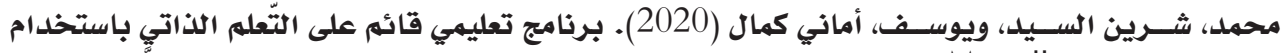

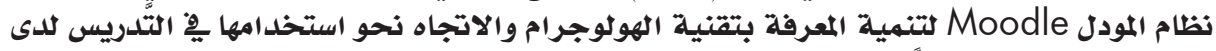

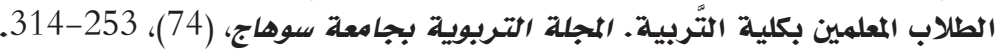

Cavus, N. (2020). Evaluation of MoblrN m-learning system: Participants' attitudes and opinions. World Journal on Educational Technology: Current Issues. 12(3), 150-164.

Dillard, A. (2012). Mobile instructional design principles for adult learners (Master thesis), University of Oregon, Eugene, Oregon.

Jarmuz-Smith, S. (2012). Mobile app review. National Association of School Psychologists, $41(1)$, 38-38.

Kwon, S., \& Lee, J. (2010). Design Principles of m-learning for ESL. Procedia Social and Behavioral Sciences, 2, 1884-1889.

Nacheva, R., Vorobyeva, K., \& Bakaev, M. (2020). Evaluation and promotion of $\mathrm{m}$-Learning accessibility for smart education development. In A. Chugunov, I. Khodachek, Y. Misnikov \& D. Trutnev (eds.), Electronic governance and open society: Challenges in Eurasia (pp. 109-123). Berlin, Germany: Springer.

Nikou, S., \& Economides, A. (2018). Mobile-based assessment: A literature review of publications in major referred journals from 2009 to 2018. International Journal of Computers \& Education, 125, 101-119.

Wang, M., \& Shen, R. (2011). Message design for mobile learning: learning theories, human cognition and design principles. British Journal of Educational Technology, 4(43), 561 -575.

West, M., \& Vosloo, S. (2015). Policy guidelines for mobile learning. Paris, France: UNESCO Publishing.

\section{Arabic Reference in Roman Scripts:}

Abdel-Aty, Hassan Al-Batea (2015). Tawzif tatbiqat al'ajhizat alnnqalt aldhakiat wallawhiat fi alttelm al'iiliktrunii. Majalat Jeel Aleulum Al'iinsaniat Waliaijtimaeiati, (9), 167-179.

Abdel-Wahab, Mohammad Mahmoud (2019). Tawzif baed tatbiqat aljawaal fi alttdryb ean bued litanmiat maharat aistikhdam mawaqie albathi almubashir fi alttadrys ladaa 'aeda' hayyat alttadrys. Almajalat Altarbawiat Bikuliyat Alttarbyt Jamieat Suhaj, (59), 641-667. 


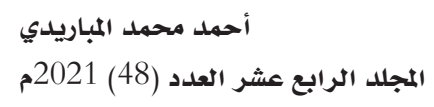

Abdul Latif, Safa Muhammad, Al-Shaaeir, Hanan Muhammad, wa Al-Mutassim, Amira Muhammad (2016). Tatwir bitaqat litaqyim biyat altaealum alnaqaal fi daw' almaeayir alealamiat litiknulujia altaelimi. Majalat Albahth Aleilmii fi Altarbiati, (7), 203-237.

Al-Assaf, Hamza Abdel-Fattah, wa Daradkeh, Amjad Mahmoud (2016). Namudhai muqtarah libiyat tuealum iilikturuniat liltaealum aljawaal fi Jamieat Alsharq Al'awsat fi daw' maeayir alttelm aljawali. Almajalat Alduwliat Lileulum Altarbawiat Walnafsiati, (3), 12-39.

Al-Baduw, Amal Muhammad (2017). 'Athar alttadrys biaistikhdam alttelm alnnqal ealaa tanmiat altahsil aldirasii limadat alriyadiaat ladaa talabat alsafi aleashir fi Al'urdun. Majalat Alraasikhun, 3(1), 1-26.

Al-Dahshan, Jamal Ali (2015). Altaelim walttelm fi zili al'ajhizat almahmulati. Alqahira: Dar Jawana Lilnashr Waltawziei.

Al-Dariwish, Ahmed Abdullah (2020). Maeayir bina' biyaat alttelm alnnqal liltalamidh alsam. Almajalat Aldawliat Lilbuhuth fi Aleulum Altarbawiati, $3(2), 155-230$.

Al-Ghoul, Reham Mohamed, wa Amin, Amin Salah El-Din (2013). 'Athar aikhtilaf 'asalib tanzim muhtawi baramii altaealum almutanaqil ealaa tanmiat maharat 'iintai albaramii al'iiliktruniat altafaeuliat ladaa 'aeda' hayyat altadrisi. Majalat Dirasat fi Almanahij Waturuq Altadrisi, (200), 66-113.

Al-Halfawi, Walid Salem (2011). Altaelim al'iiliktruniu tatbiqat mustahdithatun. Alqahira: Dar Alfikr Alearabii.

Al-Jawda, Majid Mahmoud (2013). Astikhdam namudhai almuhawalat dhi alhadayn fi fahs taqdirat almuhakamin limaqayis aliatijahati. Majalat Aljamieat Al'iislamiat Lildirasat Altarbawiat Walnafsiati, $21(1)$, 407-434.

Al-Juhani, Laila (2014). 'Usus tasmim altatbiqat altaelimiat almustakhdamat eabr alhawatif almutanaqilat walhawasib allawhiati. Majalat Ealam Alttarbyt, 15(46), 65-104.

Al-Rifai, Ahmed Mohamed (2015). Jawdat aistikhdam 'ajhizat alttelm alnnqal fi eamaliaat altaelimi. Almutamar Alduwaliu Alraabie Liltaelim Al'iiliktrunii Waltaelim ean Bueda, 2-5 Mars, Alriyad.

Al-Saidi, Omar Salem (2011). Almaeayir allaazimat litaqdim muhtawaa almuqararat al'iiliktruniat fi alttelym ean bued min wijhat nazar alkhubara' walmukhtasiyna. Majalat Rabitat Alttarbyt Alhadithati, 4(10), 171-221. 
Al-Salami, Zainab Hassan, wa Khamis, Muhammad Attiya (2009). Maeayir tasmim watatwir baramii alkumbiutar mutaeadidat alwasayit alqayimat ealaa saqalat alttelm althaabitat walmurinati. Almutamar Aleilmiu Althaani Eashar Hawl Tiknulujia Altaelim Al'iiliktrunii bayn Tahadiyat Alhadir wa Afaq Almustaqbali. 28-29 'Oktubar, Aljameiat Almisriat Litiknulujia Altaelimi, Jamieat Eayn Shams, Alqahira, Misr.

Amin, Zainab Muhammad (2015). Almustahdathat altiknulujiat rua watatbiqati. Alqahira: Almuasasat Alearabiat Lileulum Walthaqafati.

El-Shahat, Suzan Mahmoud (2014). Namudhai muqtarah litawzif alttelm almutanaqil fi almawaqif altaelimiat wafaeaaliatih ealaa talamidh alhalqat al'iiedadia (Risalat majistir), Jamieat Eayn Shams, Misr.

Hamza, Ihab Muhammad, wa Al-Aimi, Nada Salem (2013). Almaeayir altarbawiat walfaniyat litawzif alttelm almutanaqil fi baramii altadrib al'iliktrunii bidawlat Alkuayt. Majalat Dirasat Arabiat fi Alttarbyt Waeilm Alnafsi, 4(43), 1-51.

Hijazi, Rehab Ali, Tolba, Abdel Aziz Abdel Hamid, Abdel Karim, Mona Issa, wa Hakim, Reda Gerges (2020). Faeiliat baed tatbiqat altaealum alnaqaal fi tanmiat altahsil walainkhirat fi altaealum ladaa tulaab tiknulujia altaelimi. Majalat Altarbiat Alnaweiati, (1 1), 60-92.

Jawdat, Mustafa (Ynayar 6, 2015). Tatbiqat alttelm almutanaqil Mobile Learning Application. Astarjie min Bawaabat Tiknulujya Altaelima: http://drgawdat.edutech-portal.net/archives/13600

Khamis, Mohamed Attiya (2007). Alkumbiutar altaelimiu watiknulujia alwasayit almutaeadidati. Alqahira: Dar Alsahab Lilnashr Waltawziei.

Khamis, Mohamed Attiya (2011). Al'usul alnazariat waltaarikhiat litiknulujia altaelim al'iilikturunii. Alqahira: Dar Alsahab Lilnashr Waltawziei.

Mohamed, Shereen El-Sayed, wa Youssef, Amani Kamal (2020). Barnamai taelimiun qayim ealaa alttelm aldhaatii biastikhdam nizam almudil Moodle litanmiat almaerifat bitiqniat alhuluiram walaitijah nahw aistikhdamiha fi alttadrys ladaa altulaab almuealimin bikuliyat alttarby. Almajalat Altarbawiat Bijamieat Suhai, (74), 253-314.

Qarqaii, Ashwaq Dahman (2020). Tasmim tatbiq 'iilikturuniin qayim ealaa alttelm almutanaqil wataqyimih wifa maeayir muhadadati. Almajalat Altarbawiat bi Jamieat Suhai, (72), 295-346.

Ramoud, Rabea Abdel Azim, wa Abdel Hamid, Wael Ramadan (2014). Alealaqat bayn namat al'iibhar altakayfii ('iizhari/ 'iikhfa' alrawabiti) bibiyat alttelm al'iiliktrunii almutanaqil wa'uslub alttelm (hsi/ hadsi) wa'atharuha fi tanmiat altafkir alabtikari. Dirasat Arabiatan fi Alttarbyt Waeilm Alnafsi, 3(56), 53114. 
أحمد محمد المباريدي

المجلد الرابع عشر العدد (48) 2021م أحمد مياريدي

Shafiqa, Hani (2016). Faeiliat nizam 'iidarat almuhtawaa al'iiliktrunii alqayim ealaa alhatif alnnqal fi tanmiat baed maharat aistikhdam almustahdathat altiknulujiat ladaa muealimi almarhalat al'iiedadiati. Majalat Buhuth Arabiat fi Majalat Alttarbyt Alnaweiati, (1), 47-104. 